\title{
A High-Low Model of Daily Stock Price Ranges
}

\author{
YAN-LEUNG CHEUNG \\ YIN-WONG CHEUNG \\ ALAN T.K. WAN
}

\author{
CESIFO WORKING PAPER NO. 2387 \\ CATEgory 6: MONETARY POLICY AND INTERNATIONAL FinANCE \\ SEPTEMBER 2008
}
An electronic version of the paper may be downloaded
- from the SSRN website: Www.SSRN.com
- from the RePEc website: Www.RePEc.org
- from the CESifo website: www.CESifo-group.org/wp




\title{
A High-Low Model of Daily Stock Price Ranges
}

\begin{abstract}
We observe that daily highs and lows of stock prices do not diverge over time and, hence, adopt the cointegration concept and the related vector error correction model (VECM) to model the daily high, the daily low, and the associated daily range data. The in-sample results attest the importance of incorporating high-low interactions in modeling the range variable. In evaluating the out-of-sample forecast performance using both mean-squared forecast error and direction of change criteria, it is found that the VECM-based low and high forecasts offer some advantages over some alternative forecasts. The VECM-based range forecasts, on the other hand, do not always dominate - the forecast rankings depend on the choice of evaluation criterion and the variables being forecasted.
\end{abstract}

JEL Code: C32, C53, G10.

Keywords: daily high, daily low, VECM model, forecast performance, implied volatility.

Yan-Leung Cheung

Department of Economics and Finance

City University of Hong Kong

Tat Chee Avenue

Kowloon, Hong Kong

efsteven@cityu.edu.hk
Yin-Wong Cheung

Department of Economics, E2

University of California

Santa Cruz, CA 95064

USA

cheung@ucsc.edu

Alan T.K. Wan

Department of Management Sciences

City University of Hong Kong

Tat Chee Avenue

Kowloon, Hong Kong

msawan@cityu.edu.hk

Excellent research assistance was provided by Bonnie Wong. The views contained herein are solely those of the authors, and do not necessarily represent those of the institutions they are associated with. 


\section{Introduction}

Data on daily ranges of various financial prices are quite widely available. It is conceived that volatility is high (low) when the daily range is wide (narrow). Parkinson (1980) shows that, under certain assumptions, the price range is a more efficient volatility estimator than, say, the commonly used return-based estimator. Modifications and variations of the original Parkinson result are provided by, for example, Beckers (1983), Garman and Klass, (1980), Kunitomo (1992), Rogers and Satchell (1991), and Yang and Zhang (2000). Recently, there are a few studies investigating the stochastic properties of financial price ranges and using the price range as an input in various GARCH and stochastic volatility models to exploit its information content (Alizadeh et. al., 2002; Brandt and Diebold, 2003; Brunetti and Lildholdt 2005; Chou, 2005; Engle and Gallo, 2003; Fernandes et. al., 2005; Gallant et. al., 1999). Usually, the price range is touted as an efficient proxy for volatility, which is a crucial element in the modern financial literature. An early example of using the price range in options pricing is provided by Parkinson (1977).

The price range also occupies a unique role in technical analysis, which is quite widely used by traders in financial markets (Cheung and Wong, 2000; Cheung and Chinn, 2001; Taylor and Allen, 1992; Pring, 2002). For instance, the price range is a key ingredient of the well-known technical indicator candlestick, which has been used by Japanese rice traders for a very long time. The stochastic oscillator is another technical indicator that is related to the price range. The "Notis \%V" method separates price volatility into upward and downward components and compares them with the total volatility (Edwards and Magee 1997, Murphy, 1986, Pring, 2002).

Most studies on range assert its role of being an efficient proxy for the underlying return volatility. The focus on daily range, nonetheless, may neglect the value of its two components, namely the daily high and the daily low, which contain some useful information about the price dynamics. The daily range is constructed from the highest and lowest price of the day. It is, however, not easy to re-construct the high and the low from the range itself. For instance, the pricing of some exotic options such as the knock-out and knock-in options depends on, in addition to the underlying volatility, the high and the low. ${ }^{1}$ The interpretation of candlestick charts and the computation of stochastic oscillators also require the knowledge of the values of

\footnotetext{
$1 \quad$ These options are also known as barrier options. A knock-out option will expire and become worthless when the price reaches a pre-specified level.
} 
highs and lows. The high and the low are also the key components of trading strategies based on the notion of support and resistance levels and the price channel indicator. ${ }^{2}$

In essence, the price range gives the width of the band within which the price fluctuates, and the high and the low identify the exact coverage of the price band. If the interest is only the volatility, then the price range is a good summary statistics. On the other hand, if the extreme levels are also relevant, then we have to consider the high and the low. Thus, it is of interest to study both the range and its two components (the high and the low) simultaneously. Moreover, the range is given by the difference of the high and the low - knowing the high and low should potentially enhance the modeling of the range variable.

The current study exploits the following observation: for most active stock markets, daily highs and lows do not drift apart too far over time. An analogy is that stock return volatility does not trend upward all the time. The boundedness hints at the potential gain of incorporating the interaction of highs and lows in modeling the range variable. Specifically, using jargon in time series analysis, we anticipate daily highs and lows to be cointegrated such that they do not diverge over time and the range is the corresponding error correction term. If this is the case, we can exploit the interactions between the range and its two components and use the information to build an efficient model to describe the behavior and evolution of these variables.

To explore the idea, we first examine eight daily stock indexes and formally test whether a) their highs and lows are cointegrated, and b) their ranges can be interpreted as a stationary error correction term. To anticipate the results, we find that the high and the low are cointegrated and the range is the error correction term. Then, we assess the potential gains of jointly analyzing the three price variables by comparing the range forecasts generated from the cointegration framework and from autoregressive-moving-average models of ranges, highs, and lows. The mean-squared forecast error and direction of change criteria are used to compare these forecasts. We also break down the forecast errors and the forecast error variances of these range forecasts to gain further insight on their performance. As an illustration, we use these range forecasts to generate predictions of implied volatility for a few selected index options contracts. Both range and implied volatility forecasting exercises attest to the value of modeling highs, lows, and ranges simultaneously.

$2 \quad$ Support and resistance levels are price levels at which there are a possible reverse of the trend. The price channel initiates a buy (sell) when the price closes above (below) the upper (lower) channel constructed from daily 


\section{Preliminary Analyses}

In this study we consider the following daily stock indexes: the British FTSE 100 (FTSE), French CAC 40 (FCHI), the German DAX 30 (GDAX), the Japanese Nikkei 225 (N225), the Korean KOSPI (KS11), US Dow Jones Industrial Average (DJI), the US Nasdaq Composite (IXIC), and the Taiwanese TSEC Weighted index (TWII). The data are expressed in log scale. Daily ranges are constructed from the corresponding daily highs and lows for the period January 3, 1991 to June 1, 2004. The first twelve years of data (from January 3, 1991 to January 15,2003 ) are used to generate the estimation results reported in this and the next section. The remaining data are reserved for the forecasting exercise discussed in section 4 . The data were downloaded from the DataStream database.

Figure 1 gives the plots of the high and low series and their corresponding ranges. For these stock indexes, the highs and lows display different variation patterns during the sample period. However, for each stock index, it is quite transparent that highs and lows move in tandem. The gap between the high and low curves is quite stable. The range variable appears quite stationary, with some occasional spikes, in all these graphs.

To formally assess the dynamic properties of these series, we use the augmented DickeyFuller (ADF) test to determine their order of integration property. The ADF test is based on the regression equation,

$$
\Delta Y_{t}=\delta+\beta t+\gamma Y_{t-1}+\sum_{j=1}^{p} \beta_{j} \Delta Y_{t-j}+\varepsilon_{t},
$$

where $Y_{t}$ is a generic notation of a stock index daily high $\left(H_{t}\right)$, or daily low $\left(L_{t}\right)$ series, in logarithms. $\Delta$ is the first-difference operator, $\delta$ and $t$ are, respectively, an intercept and time trend, and $\varepsilon_{t}$ is the error term. Under the unit-root hypothesis, $\gamma=0$. The Schwarz-Bayesian information criterion (SBC) is used to determine $p$, the lag parameter.

highs and lows. 
Figure 1. Highs (H), Lows (L), and Ranges (R).
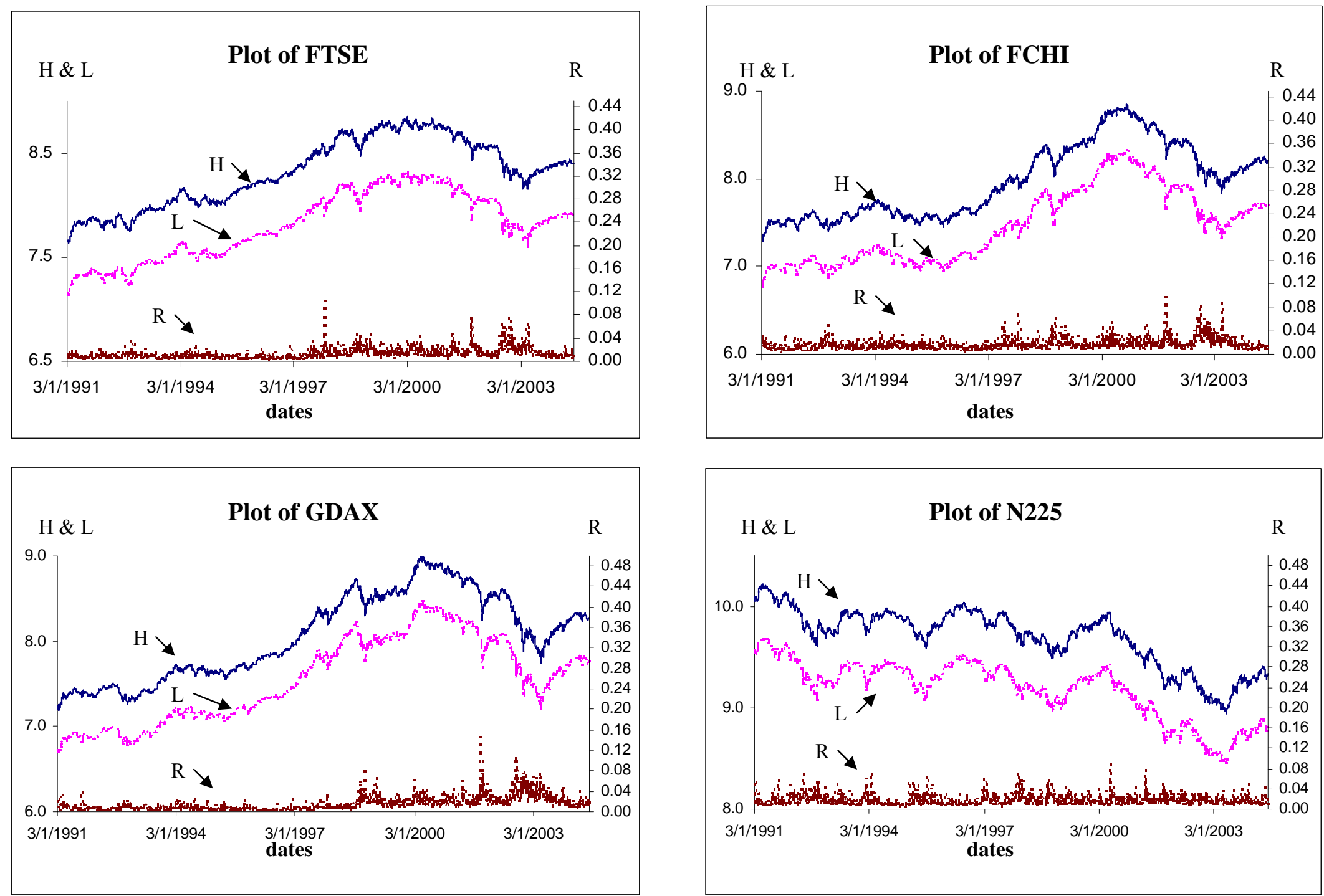

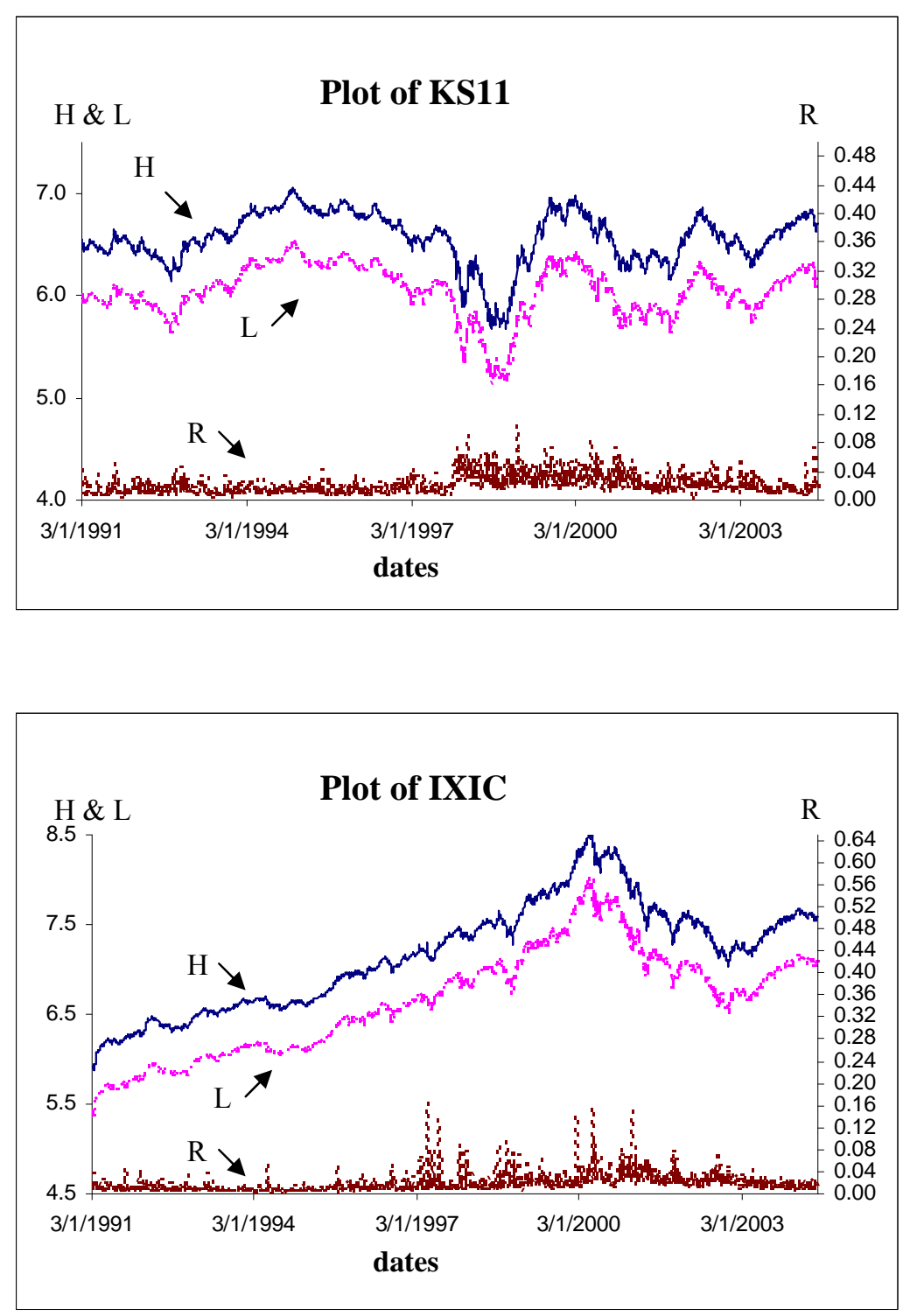
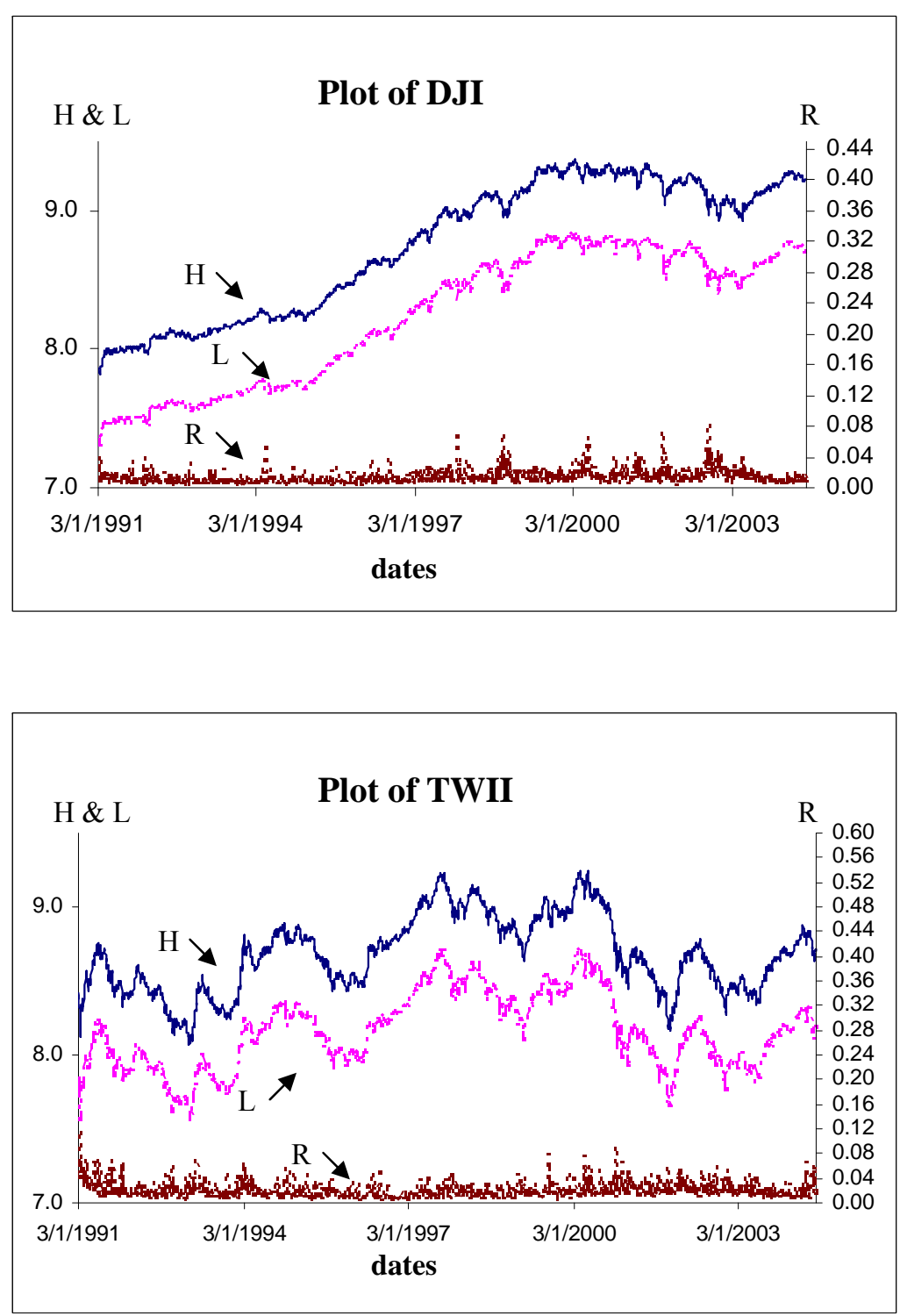

Note: $\mathrm{H}$ is the daily high series. To improve visibility, $\mathrm{L}$ is the daily low series minus 0.5 , and $\mathrm{R}$ is the daily range. 
The test results are given in Table 1. The Q-statistics indicate that the lag specifications used to conduct these tests adequately capture the intertemporal dynamics. All the daily high and daily low series do not reject the unit-root null hypothesis. The test results from first-differences of these data series tell a different story. In this case, only a constant term was included in the ADF regression equation. The ADF test indicates that all the first-differenced daily high and daily low series reject the unit root null hypothesis; that is, the first-differenced data are $\mathrm{I}(0)$. Hence, in the following analyses, we assume individual daily high and daily low series are I(1) processes.

Table 1 also gives the unit root test results for individual range series. The range variable is given by $R_{t}=H_{t}-L_{t}$. In contrast to the daily high and daily low series, all the range series reject the unit root hypothesis and, hence, are stationary. The stationarity result indicates that, even though the daily high and daily low are nonstationary, their I(1) behavior offsets each other over time, and the range (which is the difference of these two variables) is stationary. A formal analysis of the cointegrating property of high and low data is presented in the next section.

Some descriptive statistics of the ranges and their components in first differences are presented in Table 2. The first differences of $H_{t}$ and $L_{t}$ are considered because $H_{t}$ and $L_{t}$ themselves are I(1). For all the stock indexes under consideration, the intra-day variation given by the sample mean of daily ranges is 30 times (DJ) to over 1000 times (KS11) larger than the day-to-day change measured by the sample average of either changes in daily highs or daily lows. The dispersion of daily ranges, on the other hand, is much smaller than that of changes in the highs and lows - the coefficients of variation computed from daily range data are at least 30 times less than those from daily highs and daily lows. The range and its two components in first differences appear to have different skewness properties. The stock index range series are skewed to the right while their two components are all skewed to the left. On the peakedness or the so-called fat-tail property, all the series are leptokurtic and have an excess kurtosis coefficient larger than that of a normal. In general, the range series has a larger kurtosis coefficient and is more leptokurtic than its two components.

These descriptive statistics suggest that the behavior of the range $R_{t}$ and $\Delta H_{t}$, and $\Delta L_{t}$ can be quite different. In fact, the properties of $\Delta H_{t}$ are different from those of $\Delta L_{t}$ even 
Table 1. Unit Root Test Results for Daily Highs, Daily Lows, and Daily Ranges

\begin{tabular}{|c|c|c|c|c|c|c|}
\hline & \multicolumn{3}{|c|}{ Levels } & \multicolumn{3}{|c|}{ First Differences } \\
\hline & $\mathrm{ADF}(\mathrm{p})$ & Q-Stat(6) & Q-Stat(12) & $\operatorname{ADF}(p)$ & Q-Stat(6) & Q-Stat(12) \\
\hline FTSE: High & $-0.12(2)$ & $\begin{array}{c}9.66 \\
(0.1396)\end{array}$ & $\begin{array}{c}14.73 \\
(0.2567)\end{array}$ & $-40.26(1)$ & $\begin{array}{c}9.74 \\
(0.1362)\end{array}$ & $\begin{array}{c}14.76 \\
(0.2549)\end{array}$ \\
\hline Low & $-0.26(8)$ & $\begin{array}{c}0.09 \\
(1.0000)\end{array}$ & $\begin{array}{c}13.02 \\
(0.3677)\end{array}$ & $-19.67(7)$ & $\begin{array}{c}0.09 \\
(1.0000)\end{array}$ & $\begin{array}{c}13.06 \\
(0.3647)\end{array}$ \\
\hline Range & $-8.05(7)$ & $\begin{array}{c}0.93 \\
(0.9880)\end{array}$ & $\begin{array}{c}18.00 \\
(0.1156)\end{array}$ & & & \\
\hline FCHI: High & $-0.71(2)$ & $\begin{array}{c}10.62 \\
(0.1007)\end{array}$ & $\begin{array}{c}13.40 \\
(0.3406)\end{array}$ & $-32.66(2)$ & $\begin{array}{c}6.84 \\
(0.3356)\end{array}$ & $\begin{array}{c}9.80 \\
(0.6333)\end{array}$ \\
\hline Low & $-0.61(6)$ & $\begin{array}{c}0.03 \\
(1.0000)\end{array}$ & $\begin{array}{c}14.09 \\
(0.2949)\end{array}$ & $-24.67(5)$ & $\begin{array}{c}0.03 \\
(1.0000)\end{array}$ & $\begin{array}{c}14.05 \\
(0.2973)\end{array}$ \\
\hline Range & $-8.97(7)$ & $\begin{array}{c}2.67 \\
(0.8487)\end{array}$ & $\begin{array}{c}14.97 \\
(0.2433)\end{array}$ & & & \\
\hline GDAX: High & $0.20(4)$ & $\begin{array}{c}5.68 \\
(0.4604)\end{array}$ & $\begin{array}{c}17.35 \\
(0.1369)\end{array}$ & $-26.52(3)$ & $\begin{array}{c}5.60 \\
(0.4698)\end{array}$ & $\begin{array}{c}17.29 \\
(0.1390)\end{array}$ \\
\hline Low & $0.06(9)$ & $\begin{array}{c}0.05 \\
(1.0000)\end{array}$ & $\begin{array}{c}18.24 \\
(0.1086)\end{array}$ & $-18.06(8)$ & $\begin{array}{c}0.05 \\
(1.0000)\end{array}$ & $\begin{array}{c}18.23 \\
(0.1090)\end{array}$ \\
\hline Range & $-6.17(8)$ & $\begin{array}{c}0.18 \\
(0.9999)\end{array}$ & $\begin{array}{c}11.33 \\
(0.5008)\end{array}$ & & & \\
\hline N225: High & $-1.74(2)$ & $\begin{array}{c}6.54 \\
(0.3656)\end{array}$ & $\begin{array}{c}11.30 \\
(0.5034)\end{array}$ & $-39.02(1)$ & $\begin{array}{c}6.33 \\
(0.3872)\end{array}$ & $\begin{array}{c}10.63 \\
(0.5610)\end{array}$ \\
\hline Low & $-1.99(2)$ & $\begin{array}{c}5.10 \\
(0.5313)\end{array}$ & $\begin{array}{c}9.43 \\
(0.6654)\end{array}$ & $-38.00(1)$ & $\begin{array}{c}5.70 \\
(0.4571)\end{array}$ & $\begin{array}{c}9.34 \\
(0.6734)\end{array}$ \\
\hline Range & $-10.48(6)$ & $\begin{array}{c}3.02 \\
(0.8065)\end{array}$ & $\begin{array}{c}6.96 \\
(0.8605)\end{array}$ & & & \\
\hline KS11: High & $-2.15(2)$ & $\begin{array}{c}8.37 \\
(0.2124)\end{array}$ & $\begin{array}{c}12.22 \\
(0.4279)\end{array}$ & $-37.39(1)$ & $\begin{array}{c}8.77 \\
(0.1871)\end{array}$ & $\begin{array}{c}12.27 \\
(0.4244)\end{array}$ \\
\hline Low & $-2.11(4)$ & $\begin{array}{c}4.77 \\
(0.5736)\end{array}$ & $\begin{array}{c}11.11 \\
(0.5199)\end{array}$ & $-28.27(3)$ & $\begin{array}{c}5.01 \\
(0.5426)\end{array}$ & $\begin{array}{c}10.85 \\
(0.5418)\end{array}$ \\
\hline Range & $-8.57(7)$ & $\begin{array}{c}2.69 \\
(0.8468)\end{array}$ & $\begin{array}{c}12.78 \\
(0.3849)\end{array}$ & & & \\
\hline DJI: High & $-0.74(1)$ & $\begin{array}{c}3.00 \\
(0.8083)\end{array}$ & $\begin{array}{c}7.09 \\
(0.8516)\end{array}$ & $-48.42(0)$ & $\begin{array}{c}3.25 \\
(0.7763)\end{array}$ & $\begin{array}{c}7.22 \\
(0.8426)\end{array}$ \\
\hline Low & $-1.00(2)$ & $\begin{array}{c}7.96 \\
(0.2413)\end{array}$ & $\begin{array}{c}14.43 \\
(0.2738)\end{array}$ & $-38.91(1)$ & $\begin{array}{c}8.40 \\
(0.2104)\end{array}$ & $\begin{array}{c}14.80 \\
(0.2524)\end{array}$ \\
\hline Range & $-9.85(7)$ & $\begin{array}{c}1.22 \\
(0.9761)\end{array}$ & $\begin{array}{c}4.10 \\
(0.9815)\end{array}$ & & & \\
\hline IXIC: High & $-0.58(7)$ & $\begin{array}{c}0.01 \\
(1.0000)\end{array}$ & $\begin{array}{c}16.91 \\
(0.1529)\end{array}$ & $-20.19(6)$ & $\begin{array}{c}0.01 \\
(1.0000)\end{array}$ & $\begin{array}{c}16.79 \\
(0.1577)\end{array}$ \\
\hline Low & $-0.60(6)$ & $\begin{array}{c}0.11 \\
(1.0000)\end{array}$ & $\begin{array}{c}15.15 \\
(0.2334)\end{array}$ & $-24.55(5)$ & $\begin{array}{c}0.11 \\
(1.0000)\end{array}$ & $\begin{array}{c}14.92 \\
(0.2458)\end{array}$ \\
\hline Range & $-10.03(7)$ & $\begin{array}{c}4.16 \\
(0.6549)\end{array}$ & $\begin{array}{c}16.12 \\
(0.1857)\end{array}$ & & & \\
\hline TWII: High & $-2.03(9)$ & $\begin{array}{c}1.40 \\
(0.9656)\end{array}$ & $\begin{array}{c}14.65 \\
(0.2609)\end{array}$ & $-19.18(8)$ & $\begin{array}{c}1.43 \\
(0.9640)\end{array}$ & $\begin{array}{c}13.87 \\
(0.3089)\end{array}$ \\
\hline Low & $-2.09(1)$ & $\begin{array}{c}6.63 \\
(0.3565)\end{array}$ & $\begin{array}{c}17.62 \\
(0.1278)\end{array}$ & $-45.70(0)$ & $\begin{array}{c}7.27 \\
(0.2967)\end{array}$ & $\begin{array}{c}17.74 \\
(0.1238)\end{array}$ \\
\hline Range & $-10.06(10)$ & $\begin{array}{c}1.00 \\
(0.9857) \\
\end{array}$ & $\begin{array}{c}11.12 \\
(0.5182)\end{array}$ & & & \\
\hline
\end{tabular}


Note: The results of applying augmented Dickey-Fuller tests to individual daily high, low, and range series are reported. The stock indexes considered are the British FTSE 100 (FTSE), French CAC 40 (FCHI), the German DAX 30 (GDAX), the Japanese Nikkei 225 (N225), the Korean KOSPI (KS11), US Dow Jones Industrial Average (DJI), the US Nasdaq Composite (IXIC), and the Taiwanese TSEC Weighted index (TWII). The Box-Ljung statistics based on the first six and first twelve serial correlations of the estimated residuals are given under the heading "Q-Stat" and their p-values are given in parentheses underneath. For all the daily high and daily low series, the unit root null hypothesis is not rejected by the data themselves but is rejected by their first differences. All the range series reject the unit root null hypothesis. Critical values are from Cheung and Lai (1995).

Table 2. Descriptive Statistics

\begin{tabular}{|c|c|c|c|c|c|}
\hline & Mean & Variance & Coefficient of & Skewness & Kurtosis \\
\hline FTSE: $\Delta$ High & 0.0205 & 0.0090 & 46.3001 & -0.0955 & 2.9911 \\
\hline$\Delta$ Low & 0.0201 & 0.0114 & 53.0264 & -0.4021 & 7.6419 \\
\hline Range & 1.2693 & 0.0074 & 0.6784 & 2.4296 & 11.3541 \\
\hline FCHI: $\Delta$ High & 0.0244 & 0.0155 & 51.1345 & -0.3266 & 2.7638 \\
\hline$\Delta$ Low & 0.0243 & 0.0200 & 58.1231 & -0.1914 & 4.2217 \\
\hline Range & 1.6247 & 0.0086 & 0.5705 & 2.3404 & 9.1265 \\
\hline GDAX: $\Delta$ High & 0.0274 & 0.0164 & 46.6936 & -0.4003 & 4.7836 \\
\hline$\Delta$ Low & 0.0265 & 0.0204 & 53.9929 & -0.6592 & 5.5948 \\
\hline Range & 1.3916 & 0.0161 & 0.9112 & 2.4801 & 10.2045 \\
\hline N225: $\Delta$ High & -0.0347 & 0.0154 & -35.6901 & 0.5631 & 2.5137 \\
\hline$\Delta$ Low & -0.0348 & 0.0181 & -38.5950 & -0.0785 & 3.0672 \\
\hline Range & 1.7307 & 0.0088 & 0.5430 & 1.9087 & 6.0185 \\
\hline KS11: $\Delta$ High & -0.0017 & 0.0355 & -1080.1908 & 0.1095 & 3.4777 \\
\hline$\Delta$ Low & -0.0018 & 0.0375 & -1068.1495 & -0.0658 & 3.9044 \\
\hline Range & 2.0925 & 0.0160 & 0.6049 & 1.4384 & 2.5557 \\
\hline DJI: $\Delta$ High & 0.0402 & 0.0074 & 21.3094 & -0.0374 & 3.7671 \\
\hline$\Delta$ Low & 0.0402 & 0.0099 & 24.7507 & -0.4818 & 6.0939 \\
\hline Range & 1.3292 & 0.0063 & 0.5991 & 2.4591 & 10.9923 \\
\hline IXIC: $\Delta$ High & 0.0451 & 0.0223 & 33.1070 & -0.3748 & 12.5609 \\
\hline$\Delta$ Low & 0.0449 & 0.0318 & 39.7227 & -0.1099 & 6.4246 \\
\hline Range & 1.7482 & 0.0215 & 0.8390 & 2.7642 & 14.8014 \\
\hline TWII: $\Delta$ High & 0.0036 & 0.0282 & 463.8801 & -0.1514 & 2.8460 \\
\hline$\Delta$ Low & 0.0053 & 0.0302 & 329.3805 & -0.0755 & 3.7417 \\
\hline Range & 1.9247 & 0.0129 & 0.5898 & 1.8788 & 5.8040 \\
\hline
\end{tabular}

Note: The mean and variance are scaled by a factor of 100 . Kurtosis is normalized so that the normal distribution has a value of 0 . Also, see Note to Table 1. 
though their differences are less striking than those between them and the range. Thus, despite the three series $R_{t}, \Delta H_{t}$, and $\Delta L_{t}$ are derived from the same underlying stock index, their information contents are not identical. A joint analysis of these variables may offer incremental information about the behavior of these variables.

\section{A Joint Analysis of Highs and Lows}

\subsection{Cointegration Test}

The unit root test results in the previous section are suggestive of the cointegration between daily highs and daily lows. In this subsection, the Johansen procedure is used to formally test for cointegration. Let $\mathbf{X}_{\mathbf{t}}$ be a $2 \mathrm{x} 1$ vector containing a national stock daily high and low series (that is, $\left.\mathbf{X}_{\mathbf{t}} \equiv\left(H_{t}, L_{t}\right)^{\prime}\right)$ and has a $(\mathrm{p}+1)$-th order autoregressive representation:

$$
\mathbf{X}_{t}=\mu+\sum_{j=1}^{p+1} \gamma_{j} \mathbf{X}_{t-j}+\varepsilon_{t}
$$

where $\mu$ is an intercept term, $\gamma_{j}$ is a coefficient matrix, and $\varepsilon_{t}$ is an innovation vector. To test whether the elements in $\mathbf{X}_{\mathbf{t}}$ are cointegrated, the Johansen procedure tests for significant canonical correlations between $\Delta \mathbf{X}_{t}$ and $\mathbf{X}_{t-p-l}$, after adjusting for all intervening lags. Johansen (1991) and Johansen and Juselius (1990), for example, give a detailed description of the test. The cointegration test results are reported in Table 3. Again, the SBC is used to provide the initial estimate of the lag parameter ( $p$ ), and if necessary, $p$ is then increased to eradicate serial correlation in residuals. Both the maximum eigenvalue and trace statistics reject the null hypothesis of no cointegration in favor of the presence of one cointegrating vector. Further, there is no evidence that there exists more than one cointegrating vector. These results suggest that, for a given stock index, its daily high and daily low series are cointegrated. That is, the high and low series have the same stochastic trend that drives them individually to wander randomly over time, and an appropriate linear combination of highs and lows can eliminate the effects of the common stochastic trend.

The estimated cointegrating vectors with the coefficient of the daily high series $H_{t}$ normalized to one are also reported in Table 3. The estimated vectors, which capture the empirical long-run relationship, suggest the daily high and the daily low tend to move almost on a one-to- one basis. Recall that the range is defined by $R_{t}=H_{t}-L_{t}$. When we impose the restriction that the cointegrating vector is $(1,-1)$, the cointegrating relationship is given by 
Table 3. Cointegration Test Results

\begin{tabular}{|c|c|c|c|c|c|}
\hline & & EIGENV & TRACE & C. Vector & LAG \\
\hline FTSE & & & & $(1,-1.00899)$ & 8 \\
\hline & $\mathrm{r}=1$ & 4.28 & 4.28 & & \\
\hline & $r=0$ & $63.09^{*}$ & $67.38 *$ & & \\
\hline FCHI & & & & $(1,-1.00607)$ & 7 \\
\hline & $r=1$ & 2.11 & 2.11 & & \\
\hline & $\mathrm{r}=0$ & $90.68 *$ & $92.79 *$ & & \\
\hline GDAX & & & & $(1,-1.01124)$ & 11 \\
\hline & $\mathrm{r}=1$ & 2.45 & 2.45 & & \\
\hline & $\mathrm{r}=0$ & $48.11^{*}$ & $50.56^{*}$ & & \\
\hline N225 & & & & $(1,-0.99195)$ & 4 \\
\hline & $r=1$ & 0.22 & 0.22 & & \\
\hline & $r=0$ & $227.34 *$ & $227.56^{*}$ & & \\
\hline KS11 & & & & $(1,-0.98571)$ & 6 \\
\hline & $\mathrm{r}=1$ & 4.00 & 4.00 & & \\
\hline & $\mathrm{r}=0$ & $83.23 *$ & $87.23 *$ & & \\
\hline DJI & & & & $(1,-1.00630)$ & 8 \\
\hline & $\mathrm{r}=1$ & 3.53 & 3.53 & & \\
\hline & $\mathrm{r}=0$ & $100.97^{*}$ & $104.50^{*}$ & & \\
\hline IXIC & & & & $(1,-1.01276)$ & 8 \\
\hline & $\mathrm{r}=1$ & 4.63 & 4.63 & & \\
\hline & $\mathrm{r}=0$ & $118.72^{*}$ & $123.35^{*}$ & & \\
\hline TWII & & & & $(1,-0.99721)$ & 13 \\
\hline & $r=1$ & 4.80 & 4.80 & & \\
\hline & $r=0$ & $76.37 *$ & $81.16^{*}$ & & \\
\hline
\end{tabular}

Note: The results of testing for cointegration between highs and lows of individual stock series are reported. Eigenvalue and trace statistics are given under the columns "EIGENV" and "TRACE." " $\mathrm{r}=0$ " corresponds to the null hypothesis of no cointegration and " $\mathrm{r}=1$ " corresponds to the hypothesis of one cointegration vector. All the Q-statistics (reported in Table 4) are insignificant. The rows labeled "C. Vector" give cointegrating vectors with the coefficient of the high normalized to one. "LAG" gives the lag parameters used to conduct the test. "*” indicates significance at the $5 \%$ level.

$H_{t}-L_{t}$, and thus, the range $R_{t}$ is the stationary error correction term. Indeed, the unit root test results in Table 1 already showed that $R_{t}$ is stationary. Thus, in the balance of this paper, we 
impose the $(1,-1)$ restriction and treat $R_{t}$ is the stationary error correction term. It is noted that imposing the $(1,-1)$ restriction reduces the computing burden in conducting the forecasting exercise reported in Section 4. For brevity, we do not report in the text the results pertaining to the case in which the $(1,-1)$ restriction is not imposed. ${ }^{3}$

\subsection{Vector Error Correction Model}

Given the daily high and daily low series are cointegrated, a vector error correction model (VECM) is used to examine their long-run and short-run interactions. Imposing the $(1,-1)$ cointegrating vector restriction, the VECM can be written as

$$
\Delta \mathbf{X}_{t}=\mu+\sum_{i=1}^{p} \Gamma_{i} \Delta \mathbf{X}_{t-i}+\alpha R_{t-1}+\varepsilon_{t} .
$$

The VECM results are presented in Table $4 .{ }^{4}$ The Q-statistics are not significant and, thus, affirm that the selected VECM models adequately capture the data dynamics, and the resulting disturbance terms display no statistically significant serial correlation. Since we do not have a theoretical model underpinning the VECM (3), we do not want to over-interpret the estimation results. Nonetheless, there are a few interesting observations.

First, for each stock index series, the range variable is significant in either the daily high or the daily low equation. The result is consistent with the cointegration result and indicates that the range variable is not an unreasonable proxy for the error correct term. Indeed, in most cases, the range variable is significant. When the range variable is significant, it has a negative coefficient in the daily high equation and a positive coefficient in the daily low equation. An increase in the daily range tends to bring down the next daily high and push up the next daily low and, hence, reduces the next daily range. Thus, the estimated dynamics implies the range variable is regressive and is in accordance with its stationary property. ${ }^{5}$ For the five insignificant cases, four of them involve the daily high equation. For some reason, daily lows are more likely to respond to the range.

\footnotetext{
3 The results pertaining to models without the $(1,-1)$ restriction are available upon request. See also Cheung (2007). These results are very similar to those reported in the text. Moreover, the forecast performance of models with the $(1,-1)$ restriction is, in general, better than those without the restriction.

$4 \quad$ One technical issue specific to the current application is the non-negativity of the range variable. We checked and confirmed that all the estimated ranges and range forecasts reported in the rest of the paper are positive. Thus, it is not necessary to impose the non-negativity constraint on, say, the VECM specification.

Note that the regressive property is not inconsistent with the volatility clustering phenomenon. A stationary $\mathrm{ARCH}$ model, for example, has regressive behavior and, at the same time, can capture volatility clustering.
} 
Table 4. Vector Error Correction Models

\begin{tabular}{|c|c|c|c|c|c|c|c|c|}
\hline & \multicolumn{2}{|c|}{ FTSE } & \multicolumn{2}{|c|}{ FCHI } & \multicolumn{2}{|c|}{ GDAX } & \multicolumn{2}{|c|}{$\mathrm{N} 225$} \\
\hline & $\Delta \mathrm{High}$ & $\Delta$ Low & $\Delta \mathrm{High}$ & $\Delta$ Low & $\Delta \mathrm{High}$ & $\Delta$ Low & $\Delta \mathrm{High}$ & $\Delta$ Low \\
\hline Constant & $\begin{array}{c}0.0010 * * \\
(2.86)\end{array}$ & $\begin{array}{c}-0.0005 \\
(-1.17)\end{array}$ & $\begin{array}{c}0.0014 * * \\
(2.53)\end{array}$ & $\begin{array}{c}-0.0012^{*} \\
(-1.89)\end{array}$ & $\begin{array}{c}0.0012 * * \\
(3.32)\end{array}$ & $\begin{array}{l}0.0003 \\
(0.80)\end{array}$ & $\begin{array}{l}0.0005 \\
(0.90)\end{array}$ & $\begin{array}{c}-0.0043^{* *} \\
(-6.80)\end{array}$ \\
\hline$Z 1$ & $\begin{array}{l}-0.0597^{* *} \\
(-2.52)\end{array}$ & $\begin{array}{c}0.0499^{*} \\
(1.84)\end{array}$ & $\begin{array}{c}-0.0721^{* *} \\
(-2.27)\end{array}$ & $\begin{array}{c}0.0870 * * \\
(2.42)\end{array}$ & $\begin{array}{c}-0.0649 * * \\
(-3.17)\end{array}$ & $\begin{array}{c}-0.0073 \\
(-0.31)\end{array}$ & $\begin{array}{c}-0.0480 \\
(-1.50)\end{array}$ & $\begin{array}{c}0.2318^{* * *} \\
(6.88)\end{array}$ \\
\hline$\Delta$ High(-1) & $\begin{array}{c}-0.2649 * * \\
(-7.30)\end{array}$ & $\begin{array}{c}0.4957 * * \\
(11.88)\end{array}$ & $\begin{array}{c}-0.2135 * * \\
(-4.92)\end{array}$ & $\begin{array}{c}0.4776^{* *} \\
(9.71)\end{array}$ & $\begin{array}{c}-0.3833^{* *} \\
(-9.57)\end{array}$ & $\begin{array}{c}0.4489 * * \\
(9.68)\end{array}$ & $\begin{array}{c}-0.0855^{* *} \\
(-2.24)\end{array}$ & $\begin{array}{c}0.4565 * * \\
(11.37)\end{array}$ \\
\hline$\Delta \operatorname{Low}(-1)$ & $\begin{array}{c}0.4565^{* *} \\
(13.64)\end{array}$ & $\begin{array}{c}-0.2261^{* *} \\
(-5.88)\end{array}$ & $\begin{array}{c}0.3442 * * \\
(8.52)\end{array}$ & $\begin{array}{c}-0.2650^{* *} \\
(-5.78)\end{array}$ & $\begin{array}{c}0.4884 * * \\
(13.50)\end{array}$ & $\begin{array}{c}-0.2532 * * \\
(-6.04)\end{array}$ & $\begin{array}{c}0.3653^{* *} \\
(9.97)\end{array}$ & $\begin{array}{c}-0.1293^{* *} \\
(-3.36)\end{array}$ \\
\hline$\Delta \operatorname{High}(-2)$ & $\begin{array}{c}-0.3424^{* *} \\
(-8.31)\end{array}$ & $\begin{array}{c}0.2209^{* *} \\
(4.67)\end{array}$ & $\begin{array}{c}-0.1720^{* *} \\
(-3.64)\end{array}$ & $\begin{array}{c}0.4125^{* *} \\
(7.69)\end{array}$ & $\begin{array}{c}-0.3363^{* *} \\
(-6.94)\end{array}$ & $\begin{array}{c}0.3511^{* *} \\
(6.25)\end{array}$ & $\begin{array}{c}-0.2756^{* *} \\
(-7.06)\end{array}$ & $\begin{array}{c}0.1274^{* *} \\
(3.11)\end{array}$ \\
\hline$\Delta \operatorname{Low}(-2)$ & $\begin{array}{c}0.1996^{* *} \\
(5.24)\end{array}$ & $\begin{array}{c}-0.3329 * * \\
(-7.61)\end{array}$ & $\begin{array}{c}0.1079 * * \\
(2.47)\end{array}$ & $\begin{array}{c}-0.4339 * * \\
(-8.77)\end{array}$ & $\begin{array}{c}0.2772 * * \\
(6.28)\end{array}$ & $\begin{array}{c}-0.3698^{* *} \\
(-7.24)\end{array}$ & $\begin{array}{c}0.0965^{* *} \\
(2.61)\end{array}$ & $\begin{array}{c}-0.2389^{* *} \\
(-6.16)\end{array}$ \\
\hline$\Delta \operatorname{High}(-3)$ & $\begin{array}{c}-0.1196^{* *} \\
(-2.78)\end{array}$ & $\begin{array}{c}0.3085^{* *} \\
(6.23)\end{array}$ & $\begin{array}{c}-0.0856^{*} \\
(-1.76)\end{array}$ & $\begin{array}{c}0.3341^{* *} \\
(6.06)\end{array}$ & $\begin{array}{c}-0.1897 * * \\
(-3.56)\end{array}$ & $\begin{array}{c}0.3465^{* *} \\
(5.61)\end{array}$ & $\begin{array}{c}-0.0399 \\
(-1.10)\end{array}$ & $\begin{array}{c}0.1694 * * \\
(4.43)\end{array}$ \\
\hline$\Delta$ Low $(-3)$ & $\begin{array}{c}0.1066^{* *} \\
(2.69)\end{array}$ & $\begin{array}{c}-0.3036^{* *} \\
(-6.68)\end{array}$ & $\begin{array}{c}0.0246 \\
(0.55)\end{array}$ & $\begin{array}{c}-0.3678^{* *} \\
(-7.22)\end{array}$ & $\begin{array}{c}0.1441 * * \\
(2.95)\end{array}$ & $\begin{array}{c}-0.3645^{* *} \\
(-6.45)\end{array}$ & $\begin{array}{c}0.0797^{* *} \\
(2.33)\end{array}$ & $\begin{array}{c}-0.1162 * * \\
(-3.23)\end{array}$ \\
\hline$\Delta \operatorname{High}(-4)$ & $\begin{array}{c}-0.0616 \\
(-1.43)\end{array}$ & $\begin{array}{c}0.2938 * * \\
(5.93)\end{array}$ & $\begin{array}{c}-0.0430 \\
(-0.91)\end{array}$ & $\begin{array}{c}0.2752^{* *} \\
(5.11)\end{array}$ & $\begin{array}{c}-0.2059 * * \\
(-3.70)\end{array}$ & $\begin{array}{c}0.1994 * * \\
(3.10)\end{array}$ & $\begin{array}{c}-0.0839 * * \\
(-2.81)\end{array}$ & $\begin{array}{c}0.0350 \\
(1.12)\end{array}$ \\
\hline$\Delta \operatorname{Low}(-4)$ & $\begin{array}{c}0.0556 \\
(1.41)\end{array}$ & $\begin{array}{c}-0.2675 * * \\
(-5.88)\end{array}$ & $\begin{array}{c}0.0791^{*} \\
(1.82)\end{array}$ & $\begin{array}{c}-0.2101^{* *} \\
(-4.26)\end{array}$ & $\begin{array}{c}0.2423^{* *} \\
(4.75)\end{array}$ & $\begin{array}{c}-0.1486^{* *} \\
(-2.51)\end{array}$ & $\begin{array}{c}0.0654^{* *} \\
(2.40)\end{array}$ & $\begin{array}{c}-0.0271 \\
(-0.95)\end{array}$ \\
\hline$\Delta \operatorname{High}(-5)$ & $\begin{array}{c}-0.1108^{* *} \\
(-2.65)\end{array}$ & $\begin{array}{c}0.1734 * * \\
(3.61)\end{array}$ & $\begin{array}{c}-0.0109 \\
(-0.25)\end{array}$ & $\begin{array}{c}0.1778^{* *} \\
(3.65)\end{array}$ & $\begin{array}{c}-0.2062^{* *} \\
(-3.66)\end{array}$ & $\begin{array}{c}0.0988 \\
(1.51)\end{array}$ & & \\
\hline$\Delta \operatorname{Low}(-5)$ & $\begin{array}{c}0.0732^{*} \\
(1.91)\end{array}$ & $\begin{array}{c}-0.1974 * * \\
(-4.48)\end{array}$ & $\begin{array}{r}-0.0122 \\
(-0.31)\end{array}$ & $\begin{array}{c}-0.2063^{* *} \\
(-4.65)\end{array}$ & $\begin{array}{c}0.1778^{* *} \\
(3.43)\end{array}$ & $\begin{array}{c}-0.1489 * * \\
(-2.48)\end{array}$ & & \\
\hline$\Delta \operatorname{High}(-6)$ & $\begin{array}{c}-0.1402^{* *} \\
(-3.67)\end{array}$ & $\begin{array}{r}0.0369 \\
(0.84)\end{array}$ & $\begin{array}{c}-0.0473 \\
(-1.39)\end{array}$ & $\begin{array}{c}0.0476 \\
(1.23)\end{array}$ & $\begin{array}{c}-0.2265^{* *} \\
(-4.06)\end{array}$ & $\begin{array}{c}-0.0076 \\
(-0.12)\end{array}$ & & \\
\hline$\Delta \operatorname{Low}(-6)$ & $\begin{array}{c}0.0816^{* *} \\
(2.32)\end{array}$ & $\begin{array}{c}-0.0933^{* *} \\
(-2.31)\end{array}$ & $\begin{array}{l}0.0160 \\
(0.51)\end{array}$ & $\begin{array}{c}-0.1042 * * \\
(-2.90)\end{array}$ & $\begin{array}{c}0.1782 * * \\
(3.46)\end{array}$ & $\begin{array}{c}-0.0444 \\
(-0.75)\end{array}$ & & \\
\hline$\Delta \operatorname{High}(-7)$ & $\begin{array}{c}-0.0678^{* *} \\
(-2.28)\end{array}$ & $\begin{array}{c}0.0672 * * \\
(1.96)\end{array}$ & & & $\begin{array}{c}-0.2369^{* *} \\
(-4.40)\end{array}$ & $\begin{array}{l}-0.0969 \\
(-1.55)\end{array}$ & & \\
\hline$\Delta \operatorname{Low}(-7)$ & $0.1024^{* *}$ & $\begin{array}{l}-0.0385 \\
(-120)\end{array}$ & & & $0.2526^{* *}$ & 0.0925 & & \\
\hline$\Delta \operatorname{High}(-8)$ & & & & & $\begin{array}{c}-0.2650^{* *} \\
(-5.20)\end{array}$ & $\begin{array}{c}-0.1863^{* *} \\
(-3.16)\end{array}$ & & \\
\hline$\Delta \operatorname{Low}(-8)$ & & & & & $\begin{array}{c}0.2530^{* *} \\
(5.38)\end{array}$ & $\begin{array}{c}0.1741^{* *} \\
(3.20)\end{array}$ & & \\
\hline$\Delta \operatorname{High}(-9)$ & & & & & $\begin{array}{c}-0.1613^{* *} \\
(-3.57)\end{array}$ & $\begin{array}{c}-0.1283^{* *} \\
(-2.45)\end{array}$ & & \\
\hline$\Delta \operatorname{Low}(-9)$ & & & & & $\begin{array}{c}0.1295^{* *} \\
(3.08)\end{array}$ & $\begin{array}{c}0.1237 * * \\
(2.54)\end{array}$ & & \\
\hline$\Delta \operatorname{High}(-10)$ & & & & & $\begin{array}{l}0.0296 \\
(0.85)\end{array}$ & $\begin{array}{c}0.0449 \\
(1.12)\end{array}$ & & \\
\hline$\Delta \operatorname{Low}(-10)$ & & & & & $\begin{array}{l}-0.0257 \\
(-0.77)\end{array}$ & $\begin{array}{l}-0.0474 \\
(-1.23)\end{array}$ & & \\
\hline Adj R-2 & 0.1374 & 0.0962 & 0.0766 & 0.0776 & 0.1182 & 0.0597 & 0.1092 & 0.1626 \\
\hline Q-stat(6) & 0.40 & 0.24 & 0.37 & 0.16 & 0.15 & 0.11 & 0.42 & 1.51 \\
\hline Q-stat(12) & 7.20 & 14.54 & 5.83 & 11.27 & 10.97 & 10.60 & 5.25 & 12.52 \\
\hline
\end{tabular}




\begin{tabular}{|c|c|c|c|c|c|c|c|c|}
\hline & \multicolumn{2}{|c|}{$\underline{\mathrm{KS} 11}$} & \multicolumn{2}{|c|}{$\underline{\mathrm{DJI}}$} & \multicolumn{2}{|c|}{ IXIC } & \multicolumn{2}{|c|}{ TWII } \\
\hline & $\Delta \mathrm{High}$ & $\bar{\Delta}$ Low & $\Delta$ High & $\Delta$ Low & $\Delta$ High & $\Delta$ Low & $\Delta$ High & $\bar{\Delta}$ Low \\
\hline \multirow[t]{2}{*}{ Constant } & 0.0007 & $-0.0021 * *$ & $0.0009 * *$ & $-0.0015 * *$ & $0.0017 * *$ & -0.0007 & 0.0002 & $-0.0035 * *$ \\
\hline & $(1.00)$ & $(-2.73)$ & $(2.38)$ & $(-3.50)$ & $(3.42)$ & $(-1.18)$ & $(0.30)$ & $(-4.13)$ \\
\hline \multirow[t]{2}{*}{$Z 1$} & -0.0350 & $0.1002 * *$ & -0.0366 & $0.1314 * *$ & $-0.0712 * *$ & $0.0601 * *$ & -0.0119 & $0.1880^{* *}$ \\
\hline & $(-1.10)$ & $(3.03)$ & $(-1.44)$ & $(4.49)$ & $(-2.98)$ & $(2.09)$ & $(-0.30)$ & $(4.52)$ \\
\hline \multirow[t]{2}{*}{$\Delta \operatorname{High}(-1)$} & $-0.2610 * *$ & $0.3120 * *$ & $-0.2502 * *$ & $0.5825^{* *}$ & $-0.2748 * *$ & $0.5015^{* *}$ & $-0.3578 * *$ & $0.2683 * *$ \\
\hline & $(-5.67)$ & $(6.53)$ & $(-7.25)$ & $(14.61)$ & $(-7.88)$ & $(11.94)$ & $(-7.40)$ & $(5.28)$ \\
\hline \multirow[t]{2}{*}{$\Delta \operatorname{Low}(-1)$} & $0.5142 * *$ & -0.0222 & $0.4989 * *$ & $-0.1411 * *$ & $0.3629 * *$ & $-0.2764 * *$ & $0.5461 * *$ & -0.0309 \\
\hline & $(11.49)$ & $(-0.48)$ & $(15.76)$ & $(-3.86)$ & $(11.54)$ & $(-7.30)$ & (11.68) & $(-0.63)$ \\
\hline \multirow[t]{2}{*}{$\Delta \operatorname{High}(-2)$} & $-0.1953 * *$ & $0.2159 * *$ & $-0.3647 * *$ & $0.2330 * *$ & $-0.2885 * *$ & $0.3077 * *$ & $-0.2306 * *$ & $0.2205 * *$ \\
\hline & $(-3.94)$ & $(4.19)$ & $(-9.42)$ & $(5.21)$ & $(-7.42)$ & $(6.57)$ & $(-4.46)$ & $(4.07)$ \\
\hline \multirow[t]{2}{*}{$\Delta \operatorname{Low}(-2)$} & 0.0570 & $-0.3262 * *$ & $0.1888 * *$ & $-0.3553 * *$ & $0.2077 * *$ & $-0.3493 * *$ & $0.1974 * *$ & $-0.2170 * *$ \\
\hline & $(1.19)$ & $(-6.56)$ & $(5.45)$ & $(-8.87)$ & $(6.03)$ & $(-8.42)$ & $(3.96)$ & $(-4.15)$ \\
\hline \multirow[t]{2}{*}{$\Delta \operatorname{High}(-3)$} & $-0.0901 *$ & $0.1564 * *$ & $-0.2115^{* *}$ & $0.2584 * *$ & $-0.1876^{* *}$ & $0.3243 * *$ & $-0.2409 * *$ & $0.0917 *$ \\
\hline & $(-1.82)$ & $(3.05)$ & $(-5.30)$ & $(5.60)$ & $(-4.69)$ & $(6.74)$ & $(-4.54)$ & $(1.65)$ \\
\hline \multirow[t]{2}{*}{$\Delta \operatorname{Low}(-3)$} & $0.1348 * *$ & $-0.1349 * *$ & $0.2340 * *$ & $-0.2129 * *$ & $0.1739 * *$ & $-0.2794 * *$ & $0.2432 * *$ & -0.0724 \\
\hline & $(2.81)$ & $(-2.71)$ & $(6.56)$ & $(-5.17)$ & $(4.89)$ & $(-6.53)$ & $(4.77)$ & $(-1.35)$ \\
\hline \multirow[t]{2}{*}{$\Delta \operatorname{High}(-4)$} & 0.0497 & $0.2141 * *$ & $-0.1993 * *$ & $0.2056^{* *}$ & $-0.1006 * *$ & $0.3282 * *$ & $-0.2040 * *$ & 0.0621 \\
\hline & $(1.07)$ & $(4.45)$ & $(-5.08)$ & $(4.53)$ & $(-2.54)$ & $(6.88)$ & $(-3.81)$ & $(1.10)$ \\
\hline \multirow[t]{2}{*}{$\Delta \operatorname{Low}(-4)$} & -0.0684 & $-0.2332 * *$ & $0.1879 * *$ & $-0.1874 * *$ & $0.1198 * *$ & $-0.2680 * *$ & $0.2083 * *$ & -0.0861 \\
\hline & $(-1.53)$ & $(-5.02)$ & $(5.32)$ & $(-4.59)$ & $(3.40)$ & $(-6.32)$ & $(4.05)$ & $(-1.59)$ \\
\hline \multirow[t]{2}{*}{$\Delta \operatorname{High}(-5)$} & -0.0583 & 0.0177 & $-0.1138 * *$ & $0.1878 * *$ & $-0.0672 *$ & $0.2250 * *$ & $-0.1455 * *$ & 0.0753 \\
\hline & $(-1.52)$ & $(0.44)$ & $(-3.04)$ & $(4.34)$ & $(-1.77)$ & $(4.91)$ & $(-2.71)$ & $(1.34)$ \\
\hline \multirow[t]{2}{*}{$\Delta \operatorname{Low}(-5)$} & 0.0220 & $-0.0792 * *$ & $0.0970 * *$ & $-0.1962 * *$ & $0.0562 *$ & $-0.2627 * *$ & $0.1537 * *$ & -0.0649 \\
\hline & $(0.58)$ & $(-2.00)$ & $(2.87)$ & $(-5.03)$ & $(1.66)$ & $(-6.45)$ & $(2.98)$ & $(-1.20)$ \\
\hline$\Delta \operatorname{High}(-6)$ & & & -0.0534 & $0.1799 * *$ & 0.0265 & $0.2250 * *$ & $-0.1817 * *$ & 0.0215 \\
\hline & & & $(-1.57)$ & $(4.58)$ & $(0.77)$ & $(5.42)$ & $(-3.43)$ & $(0.39)$ \\
\hline$\Delta \operatorname{Low}(-6)$ & & & 0.0377 & $-0.1779 * *$ & -0.0226 & $-0.2467 * *$ & $0.1454 * *$ & -0.0582 \\
\hline & & & $(1.25)$ & $(-5.10)$ & $(-0.74)$ & $(-6.69)$ & $(2.84)$ & $(-1.08)$ \\
\hline$\Delta \operatorname{High}(-7)$ & & & -0.0232 & $0.0864 * *$ & $0.0491 *$ & $0.1359 * *$ & $-0.1492 * *$ & -0.0028 \\
\hline & & & $(-0.89)$ & $(2.86)$ & $(1.80)$ & $(4.13)$ & $(-2.87)$ & $(-0.05)$ \\
\hline$\Delta \operatorname{Low}(-7)$ & & & 0.0385 & $-0.0841 * *$ & -0.0034 & $-0.1287 * *$ & $0.1606^{* *}$ & 0.0112 \\
\hline & & & $(1.61)$ & $(-3.03)$ & $(-0.14)$ & $(-4.29)$ & $(3.20)$ & $(0.21)$ \\
\hline$\Delta \operatorname{High}(-8)$ & & & & & & & -0.0221 & 0.0711 \\
\hline & & & & & & & $(-0.43)$ & $(1.33)$ \\
\hline$\Delta \operatorname{Low}(-8)$ & & & & & & & 0.0615 & -0.0461 \\
\hline & & & & & & & $(1.26)$ & $(-0.90)$ \\
\hline$\Delta \operatorname{High}(-9)$ & & & & & & & -0.0712 & 0.0106 \\
\hline & & & & & & & $(-1.47)$ & $(0.21)$ \\
\hline$\Delta \operatorname{Low}(-9)$ & & & & & & & 0.0185 & -0.0552 \\
\hline & & & & & & & $(0.39)$ & $(-1.12)$ \\
\hline$\Delta \operatorname{High}(-10)$ & & & & & & & 0.0253 & $0.0873^{*}$ \\
\hline & & & & & & & $(0.55)$ & $(1.81)$ \\
\hline$\Delta \operatorname{Low}(-10)$ & & & & & & & 0.0189 & -0.0379 \\
\hline & & & & & & & $(0.43)$ & $(-0.82)$ \\
\hline$\Delta \operatorname{High}(-11)$ & & & & & & & -0.0395 & 0.0179 \\
\hline & & & & & & & $(-0.94)$ & $(0.41)$ \\
\hline$\Delta \operatorname{Low}(-11)$ & & & & & & & 0.0549 & -0.0210 \\
\hline & & & & & & & $(1.38)$ & $(-0.50)$ \\
\hline$\Delta \operatorname{High}(-12)$ & & & & & & & -0.0135 & -0.0125 \\
\hline & & & & & & & $(-0.41)$ & $(-0.36)$ \\
\hline$\Delta \operatorname{Low}(-12)$ & & & & & & & $0.0711 * *$ & 0.0464 \\
\hline & & & & & & & $(2.19)$ & $(1.36)$ \\
\hline Adj R-2 & 0.1114 & 0.0937 & 0.1683 & 0.1748 & 0.1012 & 0.0858 & 0.1161 & 0.0811 \\
\hline Q-stat(6) & 1.44 & 0.78 & 0.14 & 0.03 & 0.35 & 0.45 & 0.33 & 0.41 \\
\hline Q-stat(12) & 4.09 & 4.42 & 4.96 & 2.14 & 11.97 & 15.13 & 1.16 & 1.38 \\
\hline
\end{tabular}


Note: The estimates of the vector error correction model are reported. Results pertaining to the high and the low equations are reported under the headings " $\Delta$ High" and " $\Delta$ Low." Robust tstatistics are given in parentheses underneath the parameter estimates. The error correction term $\mathrm{Z} 1$ is given by the difference of high and low (that is, range). "**" and "*" indicate significance at the $5 \%$ and $10 \%$ level, respectively. The adjusted R-squared statistics are reported in the row labeled "Adj R-2." Q-stat(6) and Q-stat(12) give the Q-statistics calculated from the first 6 and 12 sample autocorrelations, respectively. All the Q-statistics are insignificant.

Second, for all the stock indexes under consideration, the coefficient estimates are mostly negative for lagged dependent variables and positive for other lagged variables. For instance, consider the daily high equation, where the coefficient estimates of the lagged daily high differences are mostly negative and those of the lagged daily low differences are mostly positive. The negative coefficients are indicative of the presence of regressive behavior. Higher daily highs tend to regress to a lower level, and lower daily highs tend to regress back to a higher level. On the other hand, the positive coefficients of the lagged daily low differences suggest certain spillover effects. Higher (lower) daily lows lead to higher (lower) daily highs.

Third, the explanatory power of the VECM specification is quite reasonable. The GDAX daily low equation gives the smallest adjusted R-squares statistic of $6.0 \%$ and the DJI daily low equation has the largest of $17.5 \%$. The others are mostly in the neighborhood of $10 \%$. These adjusted R-squares statistics are not small for a typical equation explaining changes in financial prices. The evidence that the daily high equation has a higher adjusted R-squares statistic than the daily low equation is not very strong - in five out of eight cases, the model explains changes in highs better than it explains changes in lows.

\section{Forecast Performance}

The preceding results are in accordance with the intuition that daily highs and lows do not drift apart over time and, hence, the range is a stationary variable. The cointegration framework and the associated VECM are the empirical constructs to exploit the interaction between daily highs, daily lows, and daily ranges. In the current section, we assess the performance of the VECM in generating range forecasts. For comparison purposes, we consider range forecasts generated from a) forecasts of daily high and low from their respective autoregressive-moving-average (ARMA) specifications, and b) an ARMA specification of the range. A naïve forecast based on a random walk specification was also considered but not 
reported for brevity. The performance of the naive forecast was consistently worse than those considered in the text. These results are available upon request.

\subsection{Forecasting Models and Evaluation Criteria}

Out-of-sample forecasts are used to assess the forecast performance. The forecasting period is from January 16, 2003 to June 1, 2004. Let $\hat{R}_{t+h}$ be the generic notation of a h-days ahead range forecast available at time $t$. The forecast horizons considered are $h=1,2$, and $4{ }^{6}$ Using the VECM specification, the forecasts $\hat{H}_{t+h}$ and $\hat{L}_{t+h}$ derived from $\Delta \hat{\mathbf{X}}_{t+h}$ are used to compute the range forecast $\hat{R}_{t+h}$, where $\Delta \hat{\mathbf{X}}_{t+h}$ is given by

$$
\Delta \hat{\mathbf{X}}_{t+h}=\mu+\sum_{i=1}^{p} \Gamma_{i} \Delta \hat{\mathbf{X}}_{t+h-i}+\alpha \hat{R}_{t+h-1} .
$$

The right-hand-side variable $\Delta \hat{\mathbf{X}}_{t+h-i}$ is replaced by $\Delta \mathbf{X}_{t+h-i}$ if $h-i \leq 0$ and $\hat{R}_{t+h-1}$ is replaced by $R_{t+h-1}$ if $h-1 \leq 0$. Two types of VECM $\hat{R}_{t+h}$ forecast are considered. The first range forecast is based only on parameter estimates reported in Section 3 and these estimates were not updated during the forecast exercise. We label this range forecast the simple VECM forecast $\hat{R}_{t+h, S V}$. The second VECM range forecast is generated with coefficients in (4) updated recursively every day and is called recursive VECM forecast $\hat{R}_{t+h, R V}$.

The performance of $\hat{R}_{t+h, S V}$ and $\hat{R}_{t+h, R V}$ is compared against two other range forecasts. The first alternative range forecast is based on ARMA specifications of the $\Delta H_{t}$ and $\Delta L_{t}$ series. Specifically, for a given stock index series, we determine the ARMA models for $\Delta H_{t}$ and $\Delta L_{t}$ using SBC, generate forecasts from the selected $\Delta H_{t}$ and $\Delta L_{t}$ models, and construct the range forecast from the $\Delta H_{t}$ and $\Delta L_{t}$ forecasts. The selected ARMA models were updated daily. We denote this forecast $\hat{R}_{t+h, A 1}$. Since $\Delta H_{t}$ and $\Delta L_{t}$ are modeled separately, the resulting range forecast does not exploit the dynamic linkage between daily highs and daily lows. The inclusion of $\hat{R}_{t+h, A 1}$ in the comparison offers some evidence on the advantage and usefulness of incorporating daily high and daily low interactions in generating range forecasts.

\footnotetext{
$6 \quad$ Christoffersen and Diebold (1998) show that, when using the conventional mean-squared forecast error measure, imposing cointegration relationship is likely to improve near-horizon rather than long-horizon forecast performance. Also, most financial market participants are interested in short-term forecasting.
} 
The second alternative range forecast is based on ARMA specifications of ranges. The ARMA specifications were updated daily. We label it $\hat{R}_{t+h, A 2}$. The forecast $\hat{R}_{t+h, A 2}$ focuses only on the dynamics of the error correction term in the VECM specification, which represents the long-term relationship between the components of the range. The choice of $\hat{R}_{t+h, A 2}$ is motivated by some extant forecasting studies using the cointegration equation. Mark (1995) and Chinn and Meese (1995), for instance, are concerned with the stability and complexity of short-run dynamics and use only the error correction term instead of the entire error correction model to generate exchange rate forecasts. Thus, the $\hat{R}_{t+h, A 2}$ is used to assess the potential loss/benefit in stripping short-term dynamics from forecasting the range. However, it should be noted that, unlike the other three range forecasts, $\hat{R}_{t+h, A 2}$ does not give information about highs and lows, which can be useful for some applications.

Two criteria are used to evaluate the four range forecasts. One criterion is based on the ubiquitous mean-squared forecast error measure. The usual rule-of-the thumb is that a better forecast gives a smaller mean-squared forecast error. In the current exercise, a modified DieboldMariano statistic, which is appropriate for one-step and multi-steps ahead forecasts, is used to compare mean-squared forecast errors of these range forecasts (Diebold and Mariano, 1995; Harvey et al., 1997). The test statistic is based on the difference between the squared forecast errors of the two forecasts under comparison. The other evaluation criterion is based on the direction of change statistic, which is given by the percentage of forecasts that correctly predict the direction of change. A value above (below) 50 percent indicates a better (worse) forecast performance than a naive model that predicts the range has an equal chance to go up or down. Not only does the direction of change statistic constitute an alternative metric, Leitch and Tanner (1991), for instance, argue that a direction of change criterion may be more relevant for profitability and economic concerns, and hence a more appropriate metric than others based on purely statistical motivations. Again, we construct modified Diebold-Mariano statistics to test a) whether the observed percentage of correct predictions is different from 50 percent and $b$ ) whether two forecast procedures display similar performance. A technical discussion of the two evaluation techniques is given in the Appendix.

Since the two evaluation criteria have different foci, it is difficult to say one is better than the other. Both criteria offer some useful information about forecasts and alternative perspective 
to evaluate their performance. While someone may prefer one criterion to the other depending on the purpose of the forecasting exercise, we view the two criteria as complementary in this exercise. $^{7}$

\subsection{Forecast Comparison}

Table 5. Modified Diebold Mariano Statistics: Mean-Squared Forecast Errors

\begin{tabular}{|c|c|c|c|c|c|c|}
\hline & $\hat{R}_{t+h, A 1} / \hat{R}_{t+h, A 2}$ & $\hat{R}_{t+h, A 1} / \hat{R}_{t+h, S V}$ & $\hat{R}_{t+h, A 1} / \hat{R}_{t+h, R V}$ & $\hat{R}_{t+h, A 2} / \hat{R}_{t+h, S V}$ & $\hat{R}_{t+h, A 2} / \hat{R}_{t+h, R V}$ & $\hat{R}_{t+h, S V} / \hat{R}_{t+h, R V}$ \\
\hline FTSE:h=1 & $3.4977 * *$ & $3.4683 * *$ & $3.4817 * *$ & 0.9187 & 0.8560 & -0.9197 \\
\hline $\mathrm{h}=2$ & $4.1230 * *$ & $3.9984 * *$ & $4.0066^{* *}$ & 1.6249 & 1.5156 & -0.0179 \\
\hline $\mathrm{h}=4$ & $3.4272 * *$ & $3.3673^{* *}$ & $3.3490 * *$ & 1.5863 & 1.4928 & 0.7530 \\
\hline FCHI: $\mathrm{h}=1$ & $3.4396 * *$ & $2.7238 * *$ & $2.7761 * *$ & -1.4393 & -1.3726 & 1.6054 \\
\hline $\mathrm{h}=2$ & $2.2571 * *$ & $2.0965 * *$ & $2.1130 * *$ & -1.3198 & -1.3052 & 0.7059 \\
\hline $\mathrm{h}=4$ & $3.2906^{* *}$ & $3.3136^{* *}$ & $3.2988^{* *}$ & -0.9941 & -1.0863 & -0.5713 \\
\hline GDAX:h=1 & $6.9791 * *$ & $6.4182 * *$ & $6.5098 * *$ & -0.6535 & -0.2770 & $2.6765^{* *}$ \\
\hline $\mathrm{h}=2$ & $3.9817 * *$ & $3.6727 * *$ & $3.7640 * *$ & $-2.2541 * *$ & $-1.8886^{*}$ & $1.8913 *$ \\
\hline $\mathrm{h}=4$ & $5.9353 * *$ & $5.7752 * *$ & $5.7800 * *$ & $-2.1844 * *$ & $-1.7200 *$ & $1.8951 *$ \\
\hline $\mathrm{N} 225: \mathrm{h}=1$ & $5.5244 * *$ & $5.1941 * *$ & $5.2182 * *$ & $-2.2768 * *$ & $-2.2327 * *$ & $2.1868 * *$ \\
\hline $\mathrm{h}=2$ & $5.0599 * *$ & $4.9498 * *$ & $4.9647 * *$ & $-2.5999 * *$ & $-2.5860 * *$ & $2.1933 * *$ \\
\hline $\mathrm{h}=4$ & $5.1786^{* *}$ & $5.0305 * *$ & $5.0371 * *$ & $-2.5854 * *$ & $-2.5741 * *$ & $2.0297 * *$ \\
\hline $\mathrm{KS} 11: \mathrm{h}=1$ & $4.0559 * *$ & $4.2214 * *$ & $4.2150 * *$ & -0.2120 & -0.2004 & 0.3545 \\
\hline $\mathrm{h}=2$ & $3.6009 * *$ & $3.7115 * *$ & $3.7123 * *$ & -0.2687 & -0.2556 & 0.3467 \\
\hline $\mathrm{h}=4$ & $4.9158^{* *}$ & $4.5233^{* *}$ & $4.5362 * *$ & -0.4792 & -0.4675 & 0.3808 \\
\hline DJI: $h=1$ & $7.5330 * *$ & $6.9994 * *$ & $7.0111^{* *}$ & -0.1244 & -0.0758 & 1.2970 \\
\hline $\mathrm{h}=2$ & $4.3960 * *$ & $4.0566^{* *}$ & $4.0601 * *$ & -1.2122 & -1.1905 & 0.4513 \\
\hline $\mathrm{h}=4$ & $4.5721^{* *}$ & $4.5656^{* *}$ & $4.5643 * *$ & -0.4856 & -0.5205 & -0.4485 \\
\hline IXIC: $\mathrm{h}=1$ & $8.2042 * *$ & $7.2709 * *$ & $7.3001 * *$ & -0.6863 & -0.5734 & $2.8570 * *$ \\
\hline $\mathrm{h}=2$ & $3.9922 * *$ & $3.3087 * *$ & $3.3446^{* *}$ & $-2.1005 * *$ & $-2.0216^{* *}$ & $2.4670^{* *}$ \\
\hline $\mathrm{h}=4$ & $4.2748^{* *}$ & $4.0626^{* *}$ & $4.0743 * *$ & $-2.1259 * *$ & $-2.0923 * *$ & $1.7989 *$ \\
\hline TWII: $\mathrm{h}=1$ & $6.0946 * *$ & $6.2100^{* *}$ & $6.1919 * *$ & 0.8348 & 0.7227 & -1.2039 \\
\hline $\mathrm{h}=2$ & $4.3654^{* *}$ & $4.5115^{* *}$ & $4.5031 * *$ & 0.5424 & 0.4703 & -0.9132 \\
\hline $\mathrm{h}=4$ & $5.7969 * *$ & $5.6604 * *$ & $5.6746^{* *}$ & 1.1277 & 1.0978 & -0.4376 \\
\hline
\end{tabular}

Note: The modified Diebold Mariano statistics that compare the performance of two forecasts based on the mean-squared forecast error criterion are presented. A positive test statistic indicates that the first one of the forecast pair has a mean-squared forecast error larger than the second one. "**" and "*" indicate significance at the $5 \%$ and $10 \%$ level respectively.

7 Recently, a utility-based evaluation metric based on a portfolio allocation problem is proposed by Abhyankar et al. (2005). 
A comparison of the mean-squared forecast errors generated by $\hat{R}_{t+h, A 1}, \hat{R}_{t+h, A 2}, \hat{R}_{t+h, S V}$ and $\hat{R}_{t+h, R V}$ is presented in Table 5. The modified Diebold and Mariano statistics are computed for each pair of forecast series. ${ }^{8,9}$ A clear picture emerges from these statistics. The $\hat{R}_{t+h, A 1}$, which ignores the interaction between highs and lows, always yields a mean-squared forecast error that is significantly larger than those of the other three range forecasts. The result attests to the importance of incorporating the high-low link in forecasting ranges.

The $\hat{R}_{t+h, A 2}$, on the other hand, performs quite well. For the British and Taiwanese stock indexes, the mean-squared forecast error of $\hat{R}_{t+h, A 2}$ is higher than those of $\hat{R}_{t+h, S V}$ and $\hat{R}_{t+h, R V}$ but the performance deterioration is not statistically significant. On the other hand, $\hat{R}_{t+h, A 2}$ has a mean-squared forecast error better than the other two forecasts in the remaining six cases and the improvement is significant in almost half of these cases. ${ }^{10}$

The modified Diebold and Mariano statistics reported in the last column of Table 5 compare the forecast performance of the two range forecasts generated from VECM models. In three out of eight cases, the recursive VECM forecast $\hat{R}_{t+h, R V}$ yields a significantly smaller mean-squared forecast error than the simple VECM forecast $\hat{R}_{t+h, S V}$. In the remaining cases, the performance of $\hat{R}_{t+h, R V}$ relative to $\hat{R}_{t+h, S V}$ can be better or worse, though the differences are not significant. The results offer a qualified support for revising the VECM model to obtain range forecasts.

The results in Table 5 can be summarized as follows. The information about short-term and long-term interactions between highs and lows helps predict daily ranges. Echoing the concern about the stability and complexity of short-run dynamics (Mark, 1995; Chinn and

$8 \quad$ In the forecast comparison exercise, the inferences are based on the asymptotic behavior of the modified Diebold-Mariano test. The forecasting period is quite long and has over 300 observations. It is also noted that the generation of finite sample critical values for the large number of cases we deal with would be computationally infeasible. The most likely outcome of such an exercise would be the performance ranking of $\hat{R}_{t+h, A 1}$ is unchanged, and it makes the detection of the performance difference between $\hat{R}_{t+h, A 2}, \hat{R}_{t+h, S V}$, and $\hat{R}_{t+h, R V}$ more rare, and, thus, leaving our basic interpretation intact.

9 The results pertaining to the original Diebold and Mariano statistics are qualitatively similar to the modified statistics reported in the text. These results are available upon request

${ }_{10}$ Strictly speaking, the results do not necessarily imply that the short-run dynamics are not useful. An alternative interpretation is that, in this case, the model with coefficient restrictions implying short-run dynamics are captured by the first differences of the high and low past values is, on average, forecasts better. 
Meese, 1995), the VECM does not forecast better than the ARMA range model, which is a stripped version of the VECM, and periodic updating the VECM estimates can lead to better forecasts. ${ }^{11}$

Table 6. Direction of Change Statistics

\begin{tabular}{|c|c|c|c|c|c|c|c|c|}
\hline & $\hat{R}_{t+h, A 1}$ & $\begin{array}{c}\text { (Correct } \\
\%)\end{array}$ & $\hat{R}_{t+h, A 2}$ & $\begin{array}{c}\text { (Correct } \\
\%)\end{array}$ & $\hat{R}_{t+h, S V}$ & $\begin{array}{c}\text { (Correct } \\
\%)\end{array}$ & $\hat{R}_{t+h, R V}$ & $\begin{array}{c}\text { (Correct } \\
\%)\end{array}$ \\
\hline FTSE: $\mathrm{h}=1$ & $-3.0019 * *$ & (41.95) & $8.8985^{* *}$ & (73.85) & $7.9336^{* *}$ & $(71.26)$ & $7.9336^{* *}$ & $(71.26)$ \\
\hline $\mathrm{h}=2$ & $-2.4157 * *$ & (43.52) & $8.9650 * *$ & (74.06) & $9.7166^{* *}$ & (76.08) & $9.8240 * *$ & (76.37) \\
\hline$h=4$ & -0.5922 & (48.41) & $7.6989 * *$ & (70.72) & $7.2682 * *$ & (69.57) & $7.3758 * *$ & (69.86) \\
\hline FCHI: $\mathrm{h}=1$ & $-2.7222 * *$ & (42.74) & $9.0206 * *$ & (74.07) & $8.5935^{* *}$ & (72.93) & $8.9138 * *$ & (73.79) \\
\hline $\mathrm{h}=2$ & -0.9621 & (47.43) & $6.4143 * *$ & $(67.14)$ & $5.9867 * *$ & $(66.00)$ & $5.7728 * *$ & $(65.43)$ \\
\hline$h=4$ & -0.6433 & (48.28) & $7.2904 * *$ & (69.54) & $7.7192 * *$ & (70.69) & $7.6120 * *$ & (70.40) \\
\hline GDAX:h=1 & $-3.8005 * *$ & (39.83) & $9.7958 * *$ & (76.22) & $10.2240^{* *}$ & (77.36) & $10.4381 * *$ & (77.94) \\
\hline & -0.8577 & (47.70) & $7.1832 * *$ & $(69.25)$ & $6.5399 * *$ & (67.53) & $6.3255^{* *}$ & (66.95) \\
\hline$h=4$ & -1.1827 & $(46.82)$ & $7.5264 * *$ & (70.23) & $7.9565 * *$ & (71.39) & $7.8490 * *$ & (71.10) \\
\hline $\mathrm{N} 225: \mathrm{h}=1$ & $-3.8562 * *$ & (39.53) & $7.8753^{* *}$ & (71.39) & $8.2012 * *$ & (72.27) & $8.5271^{* *}$ & (73.16) \\
\hline $\mathrm{h}=2$ & $-3.9163 * *$ & $(39.35)$ & $6.0920 * *$ & (66.57) & $5.8744 * *$ & (65.98) & $5.9832 * *$ & $(66.27)$ \\
\hline$h=4$ & $-3.1642 * *$ & (41.37) & $7.5285 * *$ & (70.54) & $7.5285^{* *}$ & (70.54) & $7.5285 * *$ & (70.54) \\
\hline $\mathrm{KS} 11: \mathrm{h}=1$ & $-3.7587 * *$ & $(39.76)$ & $8.2255^{* *}$ & $(72.40)$ & $8.1165 * *$ & (72.11) & $8.1165^{* *}$ & $(72.11)$ \\
\hline $\mathrm{h}=2$ & $-3.4915^{* *}$ & (40.48) & $8.2923 * *$ & (72.62) & $7.3103 * *$ & (69.94) & $7.4194 * *$ & (70.24) \\
\hline$h=4$ & $-1.9698 * *$ & (44.61) & $7.1133 * *$ & $(69.46)$ & $7.2227 * *$ & $(69.76)$ & $7.1133 * *$ & $(69.46)$ \\
\hline DJI: $h=1$ & $-8.0641 * *$ & (28.32) & $11.8273^{* *}$ & (81.79) & $11.7198^{* *}$ & $(81.50)$ & $11.6122 * *$ & $(81.21)$ \\
\hline $\mathrm{h}=2$ & $-5.1146^{* *}$ & $(36.23)$ & $7.2682 * *$ & (69.57) & $7.9142 * *$ & $(71.30)$ & $8.0219 * *$ & (71.59) \\
\hline $11-4$ & $-5.9934 * *$ & (33.82) & $9.1251^{* *}$ & (74.64) & $9.0172 * *$ & (74.34) & $9.0172 * *$ & (74.34) \\
\hline IXIC: $\mathrm{h}=1$ & $-3.9783 * *$ & (39.31) & $10.2145^{* *}$ & (77.46) & $9.7844 * *$ & (76.30) & $9.7844 * *$ & (76.30) \\
\hline $\mathrm{h}=2$ & 0.4845 & (51.30) & $7.4835^{* *}$ & (70.14) & $6.4067 * *$ & $(67.25)$ & $6.2991 * *$ & (66.96) \\
\hline $\mathrm{h}=4$ & 0.9179 & (52.48) & $7.6133 * *$ & $(70.55)$ & $7.7213 * *$ & (70.85) & $7.7213 * *$ & (70.85) \\
\hline TWII: $h=1$ & $-5.0362 * *$ & (36.36) & $8.0688 * *$ & (71.85) & $8.5020 * *$ & (73.02) & $8.6103 * *$ & $(73.31)$ \\
\hline $\mathrm{h}=2$ & $-6.1825 * *$ & (33.24) & $7.8095 * *$ & (71.18) & $7.1587 * *$ & (69.41) & $7.1587 * *$ & (69.41) \\
\hline $\mathrm{h}=4$ & $-5.5481 * *$ & $(34.91)$ & $8.5941 * *$ & $(73.37)$ & $8.3765^{* *}$ & $(72.78)$ & $8.4853 * *$ & $(73.08)$ \\
\hline
\end{tabular}

Note: The direction of change statistics for testing the hypothesis of the proportion of correct directional forecasts is 50\% are reported. "**" and "**" indicate significance at the $5 \%$ and $10 \%$ level respectively. The observed proportions of correct directional forecasts are presented in columns labeled (correct \%).

\footnotetext{
11 Indeed, we found that, for stock index series, all the coefficient estimates of the error correction term in the forecasting period are all within one-standard error bands of their respective estimates reported in Table 3 . The short-run dynamics, on the other hand, display much larger variations.
} 
Table 6 presents the direction of change statistics and the percentages of correct directional prediction. Similar to the mean-squared forecast error results, the forecast $\hat{R}_{t+h, A 1}$ offers the worst performance. In all cases under consideration, $\hat{R}_{t+h, A 1}$ has less than $50 \%$ chance predicting the correct directional variation. The other three forecasts $\hat{R}_{t+h, A 2}, \hat{R}_{t+h, S V}$ and $\hat{R}_{t+h, R V}$, on the other hand, correctly predict the movement of the range over 50 percent of the time and the improvement over the 50 percent mark is quite significant. In fact, in most cases, the percentage of correct prediction scored by these three forecasts is between $70 \%$ to $80 \%$. Thus, with the exception of $\hat{R}_{t+h, A 1}$, these range forecasts contain useful information about the movement in the range variable. 
Table 7. Modified Diebold Mariano Statistics: Direction of Change

\begin{tabular}{|c|c|c|c|c|c|c|}
\hline & $\hat{R}_{t+h, A 1} / \hat{R}_{t+h, A 2}$ & $\hat{R}_{t+h, A 1} / \hat{R}_{t+h, S V}$ & $\hat{R}_{t+h, A 1} / \hat{R}_{t+h, R V}$ & $\hat{R}_{t+h, A 2} / \hat{R}_{t+h, S V}$ & $\hat{R}_{t+h, A 2} / \hat{R}_{t+h, R V}$ & $\hat{R}_{t+h, S V} / \hat{R}_{t+h, R V}$ \\
\hline FTSE: $\mathrm{h}=1$ & $8.1803 * *$ & $7.2003 * *$ & $7.2365^{* *}$ & $-2.0745^{* *}$ & $-2.0745^{* *}$ & 0.0000 \\
\hline $\mathrm{h}=2$ & $8.6786^{* *}$ & $9.0169 * *$ & $9.1247 * *$ & 1.6171 & $1.7200^{*}$ & 0.5757 \\
\hline $\mathrm{h}=4$ & $5.8171^{* *}$ & $5.1650 * *$ & $5.1567 * *$ & -1.1588 & -0.8295 & 0.5734 \\
\hline FCHI: $h=1$ & $8.5377 * *$ & $7.9789 * *$ & $8.3689 * *$ & -0.7066 & -0.1922 & 1.0000 \\
\hline $\mathrm{h}=2$ & $5.6076^{* *}$ & $5.0429 * *$ & $4.8554 * *$ & -0.8518 & -1.2828 & -1.4204 \\
\hline $\mathrm{h}=4$ & $6.0072 * *$ & $6.2506^{* *}$ & $5.9761 * *$ & 1.0001 & 0.7242 & -0.5735 \\
\hline GDAX:h=1 & $9.5380 * *$ & $9.9217 * *$ & $10.1174 * *$ & 0.8161 & 1.1773 & 0.8161 \\
\hline $\mathrm{h}=2$ & $5.4694^{* *}$ & $4.7881 * *$ & $4.6231 * *$ & -1.3464 & $-1.8063^{*}$ & -1.4204 \\
\hline $\mathrm{h}=4$ & $5.7625^{* *}$ & $6.2011^{* *}$ & $5.9924 * *$ & 1.0707 & 0.6509 & -0.4436 \\
\hline $\mathrm{N} 225: \mathrm{h}=1$ & $7.9159^{* *}$ & $8.2463 * *$ & $8.5401 * *$ & 0.5994 & 1.2804 & $1.7372 *$ \\
\hline $\mathrm{h}=2$ & $6.5061 * *$ & $6.4759 * *$ & $6.5931 * *$ & -0.4067 & -0.2173 & 0.5756 \\
\hline $\mathrm{h}=4$ & $6.2451^{* *}$ & $6.5548 * *$ & $6.5548 * *$ & 0.0000 & 0.0000 & \\
\hline $\mathrm{KS} 11: \mathrm{h}=1$ & $7.8839 * *$ & $7.8193^{* *}$ & $7.7792 * *$ & -0.1997 & -0.2082 & 0.0000 \\
\hline $\mathrm{h}=2$ & $8.9089 * *$ & $8.0656^{* *}$ & $8.1684^{* *}$ & $-1.7479 *$ & -1.5794 & 0.4456 \\
\hline $\mathrm{h}=4$ & $6.6755^{* *}$ & $6.7119 * *$ & $6.6208^{* *}$ & 0.1674 & 0.0000 & -1.0001 \\
\hline DJI: $h=1$ & $14.5102 * *$ & $14.4288 * *$ & $14.2601 * *$ & -0.1642 & -0.3329 & -1.0000 \\
\hline $\mathrm{h}=2$ & $8.3409 * *$ & $8.5009^{* *}$ & $8.5948 * *$ & 1.1346 & 1.3510 & 1.0000 \\
\hline $\mathrm{h}=4$ & $10.5001 * *$ & $9.7571 * *$ & $9.8568 * *$ & -0.2402 & -0.2402 & 0.0000 \\
\hline IXIC: $\mathrm{h}=1$ & $10.5653^{* *}$ & $9.3059 * *$ & $9.3059 * *$ & -0.6319 & -0.6319 & 0.0000 \\
\hline $\mathrm{h}=2$ & $5.1073^{* *}$ & $4.2897 * *$ & $4.2385^{* *}$ & $-1.9116^{*}$ & $-2.0718^{* *}$ & -1.0000 \\
\hline $\mathrm{h}=4$ & $4.7110^{* *}$ & $4.7300 * *$ & $4.7300 * *$ & 0.1906 & 0.1906 & 0.0000 \\
\hline TWII: $h=1$ & $8.1079 * *$ & $8.5487 * *$ & $8.6118^{* *}$ & 0.9427 & 1.2135 & 1.0000 \\
\hline $2=2$ & $9.2236 * *$ & $8.9016^{* *}$ & $8.9972 * *$ & -1.2829 & -1.3465 & 0.0000 \\
\hline $\mathrm{h}=4$ & $8.4904 * *$ & $8.0721 * *$ & $8.2072 * *$ & -0.5734 & -0.3303 & 1.0001 \\
\hline
\end{tabular}

Note: The modified Diebold Mariano statistics that compare the performance of two forecasts based on the direction of change criterion are presented. A positive test statistic indicates that the second one of the forecast pair has a proportion of correct directional predictions larger than the first one. "**" and "*" indicate significance at the 5\% and $10 \%$ level respectively.

A natural question to ask is: "Is there a forecast that predicts the direction of change better than the others?" The answer is provided in Table 7, which reports the modified Diebold and Mariano statistics for performance comparison. Among the four forecasts, the range forecast $\hat{R}_{t+h, A 1}$ derived from individual high and low forecasts has the weakest performance. The abilities of the other three forecasts are quite comparable. While the actual percentages of correct forecasts are quite similar, $\hat{R}_{t+h, A 2}$ is marginally better than the other two VECM-based forecasts. 
The recursively generated $\hat{R}_{t+h, R V}$ usually has a percentage of correct predictions better than $\hat{R}_{t+h, S V}$ even though their differences are mostly not statistically significant. Thus, if the objective is to predict the direction of change, the more complicated VECM forecasts do not deliver results that are significantly better than the range forecast $\hat{R}_{t+h, A 2}$, which requires only the univariate ARMA technique and incurs a low computing cost.

\subsection{Decomposition of Forecast Error Variance}

Three of the four range forecasts $\hat{R}_{t+h, A 1}, \hat{R}_{t+h, A 2}, \hat{R}_{t+h, S V}$ and $\hat{R}_{t+h, R V}$ are derived from their corresponding high and low forecasts. This allows us to evaluate the performance of these three range forecasts in terms of their components. Since $R_{t}=H_{t}-L_{t}$, the range forecast error and its variance can be written as

$$
\hat{R}_{t+h}-R_{t+h}=\left(\hat{H}_{t+h}-H_{t+h}\right)-\left(\hat{L}_{t+h}-L_{t+h}\right)
$$

and

$$
\begin{aligned}
& \mathrm{V}\left(\hat{R}_{t+h}-R_{t+h}\right) \\
& =\mathrm{V}\left(\hat{H}_{t+h}-H_{t+h}\right)+\mathrm{V}\left(\hat{L}_{t+h}-L_{t+h}\right)-2 \operatorname{COV}\left(\hat{H}_{t+h}-H_{t+h}, \hat{L}_{t+h}-L_{t+h}\right) .
\end{aligned}
$$

Equation (5) breaks down the error in forecasting the range into errors in forecasting the high and the low. The variance decomposition of $\mathrm{V}\left(\hat{R}_{t+h}-R_{t+h}\right)$, on the other hand, gives the sources of range forecast uncertainty.

Because $\hat{R}_{t+h, A 2}$ does not directly involve forecasts of the high and the low, the decomposition results are only reported for the remaining three range forecasts. The results are summarized in Tables 8 to 10 .

The errors displayed by the three forecasts are quite small and, in most cases, are not statistically different from zero. The magnitude of forecast errors is, in general, increasing with the forecasting horizon. Even though these forecast errors are not statistically significant, the three forecasts tend to under-predict highs and lows such that the averages of $\left(\hat{H}_{t+h}-H_{t+h}\right)$ and $\left(\hat{L}_{t+h}-L_{t+h}\right)$ are all negative. For $\hat{R}_{t+h, A 1}$, the under-prediction of lows is more substantial than that of highs and, thus, the resulting range forecast errors are positive. Indeed, in six of the eight 
stock indexes, the averages of $\hat{R}_{t+h}-R_{t+h}$ computed for $\hat{R}_{t+h, A 1}$ are positive. In the cases of $\hat{R}_{t+h, S V}$ and $\hat{R}_{t+h, R V}$, the averages of $\hat{R}_{t+h}-R_{t+h}$ are positive in five out of eight cases.

The sample forecast error variances reported in these tables are in accordance with the results that the range forecast $\hat{R}_{t+h, A 1}$ yields a more variable forecast error than $\hat{R}_{t+h, S V}$ and $\hat{R}_{t+h, R V}$. That is, the inclusion of high and low dynamics in formulating range forecasts reduces forecast uncertainty. Further, the forecast error variance of $\hat{R}_{t+h, R V}$ is slightly better than that of $\hat{R}_{t+h, S V}$; indicating some marginal value in updating the short-term dynamics in generating range forecasts. Comparing $\mathrm{V}\left(\hat{H}_{t+h}-H_{t+h}\right)$ and $\mathrm{V}\left(\hat{L}_{t+h}-L_{t+h}\right)$ across the three tables, it is observed that the use of the VECM specification also enhances the quality of high and low forecasts by reducing their forecast error variations. The French CAC 40 and German DAX indexes (FCHI and GDAX) are the only two exceptional cases in which the forecast error variance of highs associated with $\hat{R}_{t+h, A 1}$ is slightly smaller than those associated with the two VECM-based forecasts. Another observation is that, for the three range forecasts, $\mathrm{V}\left(\hat{H}_{t+h}-H_{t+h}\right)$ tends to be smaller than $\mathrm{V}\left(\hat{L}_{t+h}-L_{t+h}\right)$; there are only seven out of 72 cases in which $\mathrm{V}\left(\hat{H}_{t+h}-H_{t+h}\right)$ is larger than $\mathrm{V}\left(\hat{L}_{t+h}-L_{t+h}\right)$. We do not have a good reason to explain the relative size of the two variances. However, we speculate the variance differential is related to the observation that stock prices are more volatile in a down market than in an up one. 
Table 8. Forecast Error Decomposition for $\hat{R}_{t+h, A 1}$

\begin{tabular}{|c|c|c|c|c|c|c|c|}
\hline & $A(\hat{r}-r)$ & $A(\hat{h}-h)$ & $A(\hat{l}-l)$ & $V(\hat{r}-r)$ & $V(\hat{h}-h)$ & $V(\hat{l}-l)$ & $2 \operatorname{cov}(\hat{h}-h, \hat{l}-l)$ \\
\hline FTSE: $\mathrm{h}=1$ & $\begin{array}{c}0.9095 \\
(0.22)\end{array}$ & $\begin{array}{c}-3.0897 \\
(-0.70)\end{array}$ & $\begin{array}{c}-3.9992 \\
(-0.80)\end{array}$ & 0.5855 & 0.6740 & 0.8716 & 0.9601 \\
\hline $\mathrm{h}=2$ & $\begin{array}{l}1.3176 \\
(0.32)\end{array}$ & $\begin{array}{c}-7.2928 \\
(-1.06)\end{array}$ & $\begin{array}{c}-8.6105 \\
(-1.13)\end{array}$ & 0.5705 & 1.6573 & 2.0308 & 3.1176 \\
\hline $\mathrm{h}=4$ & $\begin{array}{c}2.5824 \\
(0.56)\end{array}$ & $\begin{array}{c}-15.7615 \\
(-1.55)\end{array}$ & $\begin{array}{c}-18.3439 \\
(-1.63)\end{array}$ & 0.7293 & 3.5706 & 4.3851 & 7.2265 \\
\hline FCHI: $\mathrm{h}=1$ & $\begin{array}{l}0.9731 \\
(0.21)\end{array}$ & $\begin{array}{c}-3.3355 \\
(-0.52)\end{array}$ & $\begin{array}{c}-4.3086 \\
(-0.59)\end{array}$ & 0.7677 & 1.4622 & 1.8578 & 2.5522 \\
\hline $\mathrm{h}=2$ & $\begin{array}{l}1.7589 \\
(0.37)\end{array}$ & $\begin{array}{c}-7.5882 \\
(-0.76)\end{array}$ & $\begin{array}{c}-9.3472 \\
(-0.89)\end{array}$ & 0.7745 & 3.4636 & 3.8710 & 6.5601 \\
\hline $\mathrm{h}=4$ & $\begin{array}{c}2.6599 \\
(0.49)\end{array}$ & $\begin{array}{c}-17.7059 \\
(-1.22)\end{array}$ & $\begin{array}{c}-20.3658 \\
(-1.37)\end{array}$ & 1.0327 & 7.3897 & 7.7018 & 14.0588 \\
\hline GDAX: $h=1$ & $\begin{array}{c}0.7396 \\
(0.12)\end{array}$ & $\begin{array}{c}-5.7683 \\
(-0.81)\end{array}$ & $\begin{array}{c}-6.5079 \\
(-0.77)\end{array}$ & 1.3863 & 1.7605 & 2.4613 & 2.8355 \\
\hline $\mathrm{h}=2$ & $\begin{array}{l}1.4017 \\
(0.26)\end{array}$ & $\begin{array}{c}-12.7598 \\
(-1.16)\end{array}$ & $\begin{array}{c}-14.1616 \\
(-1.15)\end{array}$ & 1.0127 & 4.2172 & 5.2447 & 8.4492 \\
\hline $\mathrm{h}=4$ & $\begin{array}{c}2.7183 \\
(0.45)\end{array}$ & $\begin{array}{c}-28.3923^{*} \\
(-1.66)\end{array}$ & $\begin{array}{c}-31.1106^{*} \\
(-1.71)\end{array}$ & 1.2900 & 10.0933 & 11.4298 & 20.2332 \\
\hline $\mathrm{N} 225: \mathrm{h}=1$ & $\begin{array}{c}-0.1553 \\
(-0.03)\end{array}$ & $\begin{array}{c}-7.3324 \\
(-1.15)\end{array}$ & $\begin{array}{c}-7.1770 \\
(-1.01)\end{array}$ & 0.9000 & 1.3841 & 1.6982 & 2.1823 \\
\hline $\mathrm{h}=2$ & $\begin{array}{c}-0.9638 \\
(-0.18)\end{array}$ & $\begin{array}{c}-15.8702 \\
(-1.57)\end{array}$ & $\begin{array}{c}-14.9064 \\
(-1.38)\end{array}$ & 0.9267 & 3.4422 & 3.9232 & 6.4388 \\
\hline $\mathrm{h}=4$ & $\begin{array}{c}-0.2788 \\
(-0.05)\end{array}$ & $\begin{array}{c}-31.4777 * * \\
(-2.07)\end{array}$ & $\begin{array}{c}-31.1989^{* *} \\
(-1.97)\end{array}$ & 1.0001 & 7.7543 & 8.4517 & 15.2060 \\
\hline $\mathrm{KS} 11: \mathrm{h}=1$ & $\begin{array}{c}0.5093 \\
(0.09)\end{array}$ & $\begin{array}{c}-5.4459 \\
(-0.70)\end{array}$ & $\begin{array}{c}-5.9552 \\
(-0.69)\end{array}$ & 1.1216 & 2.0155 & 2.5357 & 3.4295 \\
\hline $\mathrm{h}=2$ & $\begin{array}{c}0.8902 \\
(0.15)\end{array}$ & $\begin{array}{c}-12.0567 \\
(-1.05)\end{array}$ & $\begin{array}{c}-12.9469 \\
(-1.01)\end{array}$ & 1.1695 & 4.4161 & 5.5597 & 8.8063 \\
\hline $\mathrm{h}=4$ & $\begin{array}{l}1.1116 \\
(0.18)\end{array}$ & $\begin{array}{c}-26.4722 \\
(-1.55)\end{array}$ & $\begin{array}{c}-27.5837 \\
(-1.44)\end{array}$ & 1.2830 & 9.7038 & 12.2432 & 20.6640 \\
\hline DJI: $h=1$ & $\begin{array}{c}0.2356 \\
(0.05)\end{array}$ & $\begin{array}{c}-0.1192 \\
(-0.03)\end{array}$ & $\begin{array}{c}-0.3548 \\
(-0.08)\end{array}$ & 0.6559 & 0.6389 & 0.6920 & 0.6750 \\
\hline $\mathrm{h}=2$ & $\begin{array}{c}0.5659 \\
(0.15)\end{array}$ & $\begin{array}{c}-0.4341 \\
(-0.07)\end{array}$ & $\begin{array}{c}-1.0000 \\
(-0.16)\end{array}$ & 0.4792 & 1.3170 & 1.4338 & 2.2715 \\
\hline $\mathrm{h}=4$ & $\begin{array}{l}1.1643 \\
(0.30)\end{array}$ & $\begin{array}{c}-1.9222 \\
(-0.21)\end{array}$ & $\begin{array}{c}-3.0865 \\
(-0.32)\end{array}$ & 0.5301 & 2.9040 & 3.2190 & 5.5929 \\
\hline IXIC: $\mathrm{h}=1$ & $\begin{array}{l}1.0236 \\
(0.21)\end{array}$ & $\begin{array}{c}-8.3923 \\
(-1.33)\end{array}$ & $\begin{array}{c}-9.4159 \\
(-1.56)\end{array}$ & 0.8130 & 1.3757 & 1.2658 & 1.8286 \\
\hline $\mathrm{h}=2$ & $\begin{array}{l}1.8977 \\
(0.46)\end{array}$ & $\begin{array}{c}-17.6201^{*} \\
(-1.93)\end{array}$ & $\begin{array}{c}-19.5178^{* *} \\
(-2.13)\end{array}$ & 0.5777 & 2.8864 & 2.9036 & 5.2123 \\
\hline $\mathrm{h}=4$ & $\begin{array}{c}2.2108 \\
(0.50)\end{array}$ & $\begin{array}{c}-38.3213^{* *} \\
(-2.90)\end{array}$ & $\begin{array}{c}-40.5321^{* *} \\
(-2.98)\end{array}$ & 0.6575 & 5.9760 & 6.3535 & 11.6721 \\
\hline TWII: $h=1$ & $\begin{array}{c}-0.3063 \\
(-0.04)\end{array}$ & $\begin{array}{c}-4.5170 \\
(-0.65)\end{array}$ & $\begin{array}{r}-4.2107 \\
(-0.59)\end{array}$ & 1.6008 & 1.6475 & 1.7408 & 1.7875 \\
\hline $\mathrm{h}=2$ & $\begin{array}{c}-0.4091 \\
(-0.06)\end{array}$ & $\begin{array}{c}-10.0144 \\
(-0.95)\end{array}$ & $\begin{array}{c}-9.6053 \\
(-0.84)\end{array}$ & 1.6336 & 3.7887 & 4.4175 & 6.5726 \\
\hline $\mathrm{h}=4$ & $\begin{array}{c}-0.2645 \\
(-0.04)\end{array}$ & $\begin{array}{c}-22.2882 \\
(-1.42) \\
\end{array}$ & $\begin{array}{c}-22.0238 \\
(-1.31)\end{array}$ & 1.7670 & 8.3639 & 9.5243 & 16.1212 \\
\hline
\end{tabular}

Note: $A(),. V($.$) , and \operatorname{cov}($.$) give the average, variance, and covariance of the variables inside parentheses and$ are scaled by a factor of $10^{4}$. The robust t-statistics for the hypothesis of $A()=$.0 are given underneath the associated $A($.$) estimates. "**” and “*” indicate significance at the 5 \%$ and $10 \%$ level. 
Table 9. Forecast Error Decomposition for $\hat{R}_{t+h, S V}$

\begin{tabular}{|c|c|c|c|c|c|c|c|}
\hline & $A(\hat{r}-r)$ & $A(\hat{h}-h)$ & $A(\hat{l}-l)$ & $V(\hat{r}-r)$ & $V(\hat{h}-h)$ & $V(\hat{l}-l)$ & $2 \operatorname{cov}(\hat{h}-h, \hat{l}-l)$ \\
\hline FTSE: $\mathrm{h}=1$ & $\begin{array}{c}-0.3860 \\
(-0.13)\end{array}$ & $\begin{array}{c}-1.6362 \\
(-0.39)\end{array}$ & $\begin{array}{c}-1.2502 \\
(-0.27)\end{array}$ & 0.3168 & 0.6185 & 0.7294 & 1.0310 \\
\hline $\mathrm{h}=2$ & $\begin{array}{c}-0.6158 \\
(-0.20)\end{array}$ & $\begin{array}{c}-3.9995 \\
(-0.59)\end{array}$ & $\begin{array}{c}-3.3837 \\
(-0.47)\end{array}$ & 0.3308 & 1.6100 & 1.7996 & 3.0787 \\
\hline $\mathrm{h}=4$ & $\begin{array}{c}-0.6229 \\
(-0.19)\end{array}$ & $\begin{array}{c}-9.0348 \\
(-0.89)\end{array}$ & $\begin{array}{c}-8.4119 \\
(-0.78)\end{array}$ & 0.3775 & 3.5326 & 4.0070 & 7.1621 \\
\hline FCHI: $\mathrm{h}=1$ & $\begin{array}{c}-0.2798 \\
(-0.08)\end{array}$ & $\begin{array}{c}-1.6527 \\
(-0.25)\end{array}$ & $\begin{array}{c}-1.3730 \\
(-0.20)\end{array}$ & 0.4811 & 1.4890 & 1.6333 & 2.6411 \\
\hline $\mathrm{h}=2$ & $\begin{array}{c}-0.3126 \\
(-0.08)\end{array}$ & $\begin{array}{c}-3.9318 \\
(-0.39)\end{array}$ & $\begin{array}{c}-3.6192 \\
(-0.37)\end{array}$ & 0.4957 & 3.4958 & 3.4251 & 6.4252 \\
\hline $\mathrm{h}=4$ & $\begin{array}{c}-0.1383 \\
(-0.03)\end{array}$ & $\begin{array}{c}-9.8918 \\
(-0.69)\end{array}$ & $\begin{array}{c}-9.7535 \\
(-0.68)\end{array}$ & 0.5456 & 7.2417 & 7.1433 & 13.8394 \\
\hline GDAX: $\mathrm{h}=1$ & $\begin{array}{c}-3.3516 \\
(-0.76)\end{array}$ & $\begin{array}{c}-8.4101 \\
(-1.18)\end{array}$ & $\begin{array}{c}-5.0586 \\
(-0.64)\end{array}$ & 0.6786 & 1.7655 & 2.1718 & 3.2587 \\
\hline $\mathrm{h}=2$ & $\begin{array}{c}-3.5449 \\
(-0.81)\end{array}$ & $\begin{array}{c}-16.6925 \\
(-1.50)\end{array}$ & $\begin{array}{c}-13.1476 \\
(-1.10)\end{array}$ & 0.6737 & 4.3208 & 5.0020 & 8.6491 \\
\hline $\mathrm{h}=4$ & $\begin{array}{c}-3.6877 \\
(-0.79)\end{array}$ & $\begin{array}{c}-35.1977 * * \\
(-2.06)\end{array}$ & $\begin{array}{c}-31.5100^{*} \\
(-1.74)\end{array}$ & 0.7517 & 10.0979 & 11.2931 & 20.6392 \\
\hline $\mathrm{N} 225: \mathrm{h}=1$ & $\begin{array}{c}3.1128 \\
(0.84)\end{array}$ & $\begin{array}{c}-9.2531 \\
(-1.51)\end{array}$ & $\begin{array}{c}-12.3659^{*} \\
(-1.81)\end{array}$ & 0.4619 & 1.2702 & 1.5892 & 2.3975 \\
\hline $\mathrm{h}=2$ & $\begin{array}{c}4.0741 \\
(1.08)\end{array}$ & $\begin{array}{c}-22.0845^{* *} \\
(-2.24)\end{array}$ & $\begin{array}{c}-26.1586^{* *} \\
(-2.45)\end{array}$ & 0.4816 & 3.2957 & 3.8456 & 6.6597 \\
\hline $\mathrm{h}=4$ & $\begin{array}{c}7.2458^{*} \\
(1.90)\end{array}$ & $\begin{array}{c}-45.4804 * * \\
(-3.02)\end{array}$ & $\begin{array}{c}-52.7263 * * \\
(-3.35)\end{array}$ & 0.4880 & 7.6270 & 8.3320 & 15.4710 \\
\hline $\mathrm{KS} 11: \mathrm{h}=1$ & $\begin{array}{c}4.7382 \\
(1.14)\end{array}$ & $\begin{array}{c}-4.4851 \\
(-0.60)\end{array}$ & $\begin{array}{c}-9.2234 \\
(-1.08)\end{array}$ & 0.5825 & 1.8881 & 2.4797 & 3.7853 \\
\hline $\mathrm{h}=2$ & $\begin{array}{c}6.3402 \\
(1.46)\end{array}$ & $\begin{array}{c}-12.7467 \\
(-1.13)\end{array}$ & $\begin{array}{c}-19.0869 \\
(-1.50)\end{array}$ & 0.6348 & 4.2969 & 5.4547 & 9.1168 \\
\hline $\mathrm{h}=4$ & $\begin{array}{c}8.6184 * \\
(1.87)\end{array}$ & $\begin{array}{c}-28.7195^{*} \\
(-1.69)\end{array}$ & $\begin{array}{c}-37.3379 * * \\
(-1.97)\end{array}$ & 0.7074 & 9.6246 & 11.9962 & 20.9134 \\
\hline DJI: $h=1$ & $\begin{array}{c}1.3614 \\
(0.51)\end{array}$ & $\begin{array}{c}0.4153 \\
(0.10)\end{array}$ & $\begin{array}{c}-0.9461 \\
(-0.23)\end{array}$ & 0.2491 & 0.5684 & 0.5845 & 0.9038 \\
\hline $\mathrm{h}=2$ & $\begin{array}{l}1.5332 \\
(0.58)\end{array}$ & $\begin{array}{c}-0.0360 \\
(-0.01)\end{array}$ & $\begin{array}{c}-1.5692 \\
(-0.25)\end{array}$ & 0.2411 & 1.2715 & 1.3800 & 2.4103 \\
\hline $\mathrm{h}=4$ & $\begin{array}{c}2.1568 \\
(0.81)\end{array}$ & $\begin{array}{c}-1.5486 \\
(-0.17)\end{array}$ & $\begin{array}{c}-3.7054 \\
(-0.39)\end{array}$ & 0.2413 & 2.8530 & 3.0618 & 5.6735 \\
\hline IXIC: $h=1$ & $\begin{array}{c}2.3422 \\
(0.70)\end{array}$ & $\begin{array}{c}-2.6272 \\
(-0.44)\end{array}$ & $\begin{array}{c}-4.9694 \\
(-0.85)\end{array}$ & 0.3858 & 1.2185 & 1.1706 & 2.0032 \\
\hline $\mathrm{h}=2$ & $\begin{array}{c}3.2522 \\
(0.99)\end{array}$ & $\begin{array}{c}-6.8614 \\
(-0.77)\end{array}$ & $\begin{array}{c}-10.1135 \\
(-1.11)\end{array}$ & 0.3725 & 2.7717 & 2.8859 & 5.2850 \\
\hline $\mathrm{h}=4$ & $\begin{array}{c}4.4012 \\
(1.31)\end{array}$ & $\begin{array}{c}-17.4055 \\
(-1.32)\end{array}$ & $\begin{array}{c}-21.8067 \\
(-1.62)\end{array}$ & 0.3897 & 5.9297 & 6.2339 & 11.7739 \\
\hline TWII: $\mathrm{h}=1$ & $\begin{array}{l}1.0549 \\
(0.22)\end{array}$ & $\begin{array}{c}-3.6091 \\
(-0.59)\end{array}$ & $\begin{array}{c}-4.6639 \\
(-0.67)\end{array}$ & 0.8059 & 1.2634 & 1.6302 & 2.0877 \\
\hline $\mathrm{h}=2$ & $\begin{array}{l}1.7541 \\
(0.36)\end{array}$ & $\begin{array}{c}-8.6197 \\
(-0.85)\end{array}$ & $\begin{array}{c}-10.3738 \\
(-0.92)\end{array}$ & 0.8295 & 3.5049 & 4.2909 & 6.9662 \\
\hline $\mathrm{h}=4$ & $\begin{array}{r}2.4209 \\
(0.48)\end{array}$ & $\begin{array}{c}-20.7162 \\
(-1.34)\end{array}$ & $\begin{array}{c}-23.1371 \\
(-1.37)\end{array}$ & 0.8730 & 8.1324 & 9.5921 & 16.8515 \\
\hline
\end{tabular}

Note: See the Note to Table 8 . 
Table 10. Forecast Error Decomposition for $\hat{R}_{t+h, R V}$

\begin{tabular}{|c|c|c|c|c|c|c|c|}
\hline & $A(\hat{r}-r)$ & $A(\hat{h}-h)$ & $A(\hat{l}-l)$ & $V(\hat{r}-r)$ & $V(\hat{h}-h)$ & $V(\hat{l}-l)$ & $2 \operatorname{cov}(\hat{h}-h, \hat{l}-l)$ \\
\hline FTSE: $\mathrm{h}=1$ & $\begin{array}{c}-0.2685 \\
(-0.09)\end{array}$ & $\begin{array}{c}-1.6806 \\
(-0.40)\end{array}$ & $\begin{array}{c}-1.4121 \\
(-0.31)\end{array}$ & 0.3177 & 0.6191 & 0.7316 & 1.0330 \\
\hline $\mathrm{h}=2$ & $\begin{array}{c}-0.4859 \\
(-0.16)\end{array}$ & $\begin{array}{c}-4.1829 \\
(-0.61)\end{array}$ & $\begin{array}{c}-3.6970 \\
(-0.51)\end{array}$ & 0.3309 & 1.6181 & 1.8036 & 3.0909 \\
\hline $\mathrm{h}=4$ & $\begin{array}{c}-0.3896 \\
(-0.12)\end{array}$ & $\begin{array}{c}-9.4081 \\
(-0.93)\end{array}$ & $\begin{array}{c}-9.0185 \\
(-0.83)\end{array}$ & 0.3764 & 3.5539 & 4.0248 & 7.2023 \\
\hline FCHI: $\mathrm{h}=1$ & $\begin{array}{c}0.0171 \\
(0.00)\end{array}$ & $\begin{array}{c}-1.7175 \\
(-0.26)\end{array}$ & $\begin{array}{c}-1.7346 \\
(-0.25)\end{array}$ & 0.4771 & 1.4875 & 1.6394 & 2.6499 \\
\hline $\mathrm{h}=2$ & $\begin{array}{c}-0.0142 \\
(-0.00)\end{array}$ & $\begin{array}{c}-4.2090 \\
(-0.42)\end{array}$ & $\begin{array}{c}-4.1948 \\
(-0.42)\end{array}$ & 0.4946 & 3.4997 & 3.4393 & 6.4444 \\
\hline $\mathrm{h}=4$ & $\begin{array}{c}0.2639 \\
(0.07)\end{array}$ & $\begin{array}{c}-10.4906 \\
(-0.73)\end{array}$ & $\begin{array}{c}-10.7545 \\
(-0.75)\end{array}$ & 0.5464 & 7.2626 & 7.1669 & 13.8831 \\
\hline GDAX: $\mathrm{h}=1$ & $\begin{array}{c}-3.3809 \\
(-0.77)\end{array}$ & $\begin{array}{c}-8.0996 \\
(-1.14)\end{array}$ & $\begin{array}{c}-4.7187 \\
(-0.60)\end{array}$ & 0.6693 & 1.7617 & 2.1630 & 3.2554 \\
\hline $\mathrm{h}=2$ & $\begin{array}{c}-3.6604 \\
(-0.84)\end{array}$ & $\begin{array}{c}-16.2622 \\
(-1.46)\end{array}$ & $\begin{array}{c}-12.6018 \\
(-1.05)\end{array}$ & 0.6681 & 4.3255 & 5.0261 & 8.6835 \\
\hline $\mathrm{h}=4$ & $\begin{array}{c}-3.9472 \\
(-0.85)\end{array}$ & $\begin{array}{c}-34.9288 * * \\
(-2.03)\end{array}$ & $\begin{array}{c}-30.9816^{*} \\
(-1.71)\end{array}$ & 0.7465 & 10.2060 & 11.3883 & 20.8479 \\
\hline $\mathrm{N} 225: \mathrm{h}=1$ & $\begin{array}{c}3.2215 \\
(0.87)\end{array}$ & $\begin{array}{c}-8.5359 \\
(-1.39)\end{array}$ & $\begin{array}{c}-11.7575^{*} \\
(-1.72)\end{array}$ & 0.4597 & 1.2701 & 1.5924 & 2.4028 \\
\hline $\mathrm{h}=2$ & $\begin{array}{c}4.1575 \\
(1.10)\end{array}$ & $\begin{array}{c}-20.5103^{* *} \\
(-2.08)\end{array}$ & $\begin{array}{c}-24.6679 * * \\
(-2.31)\end{array}$ & 0.4786 & 3.2964 & 3.8522 & 6.6699 \\
\hline $\mathrm{h}=4$ & $\begin{array}{c}7.1822 * \\
(1.89)\end{array}$ & $\begin{array}{c}-42.5050 * * \\
(-2.82)\end{array}$ & $\begin{array}{c}-49.6872 * * \\
(-3.15)\end{array}$ & 0.4856 & 7.6392 & 8.3527 & 15.5062 \\
\hline $\mathrm{KS} 11: \mathrm{h}=1$ & $\begin{array}{c}4.5069 \\
(1.08)\end{array}$ & $\begin{array}{c}-4.3297 \\
(-0.58)\end{array}$ & $\begin{array}{c}-8.8366 \\
(-1.03)\end{array}$ & 0.5825 & 1.8874 & 2.4806 & 3.7855 \\
\hline $\mathrm{h}=2$ & $\begin{array}{c}6.0083 \\
(1.38)\end{array}$ & $\begin{array}{c}-12.2117 \\
(-1.08)\end{array}$ & $\begin{array}{c}-18.2200 \\
(-1.43)\end{array}$ & 0.6348 & 4.3042 & 5.4602 & 9.1296 \\
\hline $\mathrm{h}=4$ & $\begin{array}{c}8.2113^{*} \\
(1.78)\end{array}$ & $\begin{array}{c}-27.5904 \\
(-1.62)\end{array}$ & $\begin{array}{c}-35.8017^{*} \\
(-1.89)\end{array}$ & 0.7076 & 9.6462 & 12.0192 & 20.9579 \\
\hline DJI: $h=1$ & $\begin{array}{l}1.4408 \\
(0.54)\end{array}$ & $\begin{array}{c}0.4259 \\
(0.11)\end{array}$ & $\begin{array}{c}-1.0149 \\
(-0.25)\end{array}$ & 0.2484 & 0.5677 & 0.5830 & 0.9023 \\
\hline $\mathrm{h}=2$ & $\begin{array}{l}1.5788 \\
(0.60)\end{array}$ & $\begin{array}{c}-0.0641 \\
(-0.01)\end{array}$ & $\begin{array}{c}-1.6428 \\
(-0.26)\end{array}$ & 0.2409 & 1.2709 & 1.3770 & 2.4070 \\
\hline $\mathrm{h}=4$ & $\begin{array}{c}2.1974 \\
(0.83)\end{array}$ & $\begin{array}{c}-1.6305 \\
(-0.18)\end{array}$ & $\begin{array}{c}-3.8279 \\
(-0.40)\end{array}$ & 0.2415 & 2.8565 & 3.0653 & 5.6804 \\
\hline IXIC: $h=1$ & $\begin{array}{c}2.3028 \\
(0.69)\end{array}$ & $\begin{array}{c}-2.3546 \\
(-0.40)\end{array}$ & $\begin{array}{c}-4.6574 \\
(-0.80)\end{array}$ & 0.3842 & 1.2148 & 1.1702 & 2.0009 \\
\hline $\mathrm{h}=2$ & $\begin{array}{c}3.1429 \\
(0.96)\end{array}$ & $\begin{array}{c}-6.3071 \\
(-0.70)\end{array}$ & $\begin{array}{c}-9.4500 \\
(-1.03)\end{array}$ & 0.3712 & 2.7674 & 2.8824 & 5.2786 \\
\hline $\mathrm{h}=4$ & $\begin{array}{l}4.2222 \\
(1.25)\end{array}$ & $\begin{array}{c}-16.3015 \\
(-1.24)\end{array}$ & $\begin{array}{c}-20.5237 \\
(-1.52)\end{array}$ & 0.3891 & 5.9260 & 6.2296 & 11.7665 \\
\hline TWII: $h=1$ & $\begin{array}{l}1.0080 \\
(0.21)\end{array}$ & $\begin{array}{c}-3.3765 \\
(-0.55)\end{array}$ & $\begin{array}{c}-4.3845 \\
(-0.63)\end{array}$ & 0.8078 & 1.2635 & 1.6367 & 2.0924 \\
\hline $\mathrm{h}=2$ & $\begin{array}{l}1.6888 \\
(0.34)\end{array}$ & $\begin{array}{c}-8.1182 \\
(-0.80)\end{array}$ & $\begin{array}{c}-9.8071 \\
(-0.87)\end{array}$ & 0.8308 & 3.5153 & 4.3106 & 6.9951 \\
\hline $\mathrm{h}=4$ & $\begin{array}{c}2.3018 \\
(0.45)\end{array}$ & $\begin{array}{c}-19.6353 \\
(-1.26)\end{array}$ & $\begin{array}{c}-21.9370 \\
(-1.30)\end{array}$ & 0.8735 & 8.1621 & 9.6308 & 16.9193 \\
\hline
\end{tabular}

Note: See the Note to Table 8 . 
For all the three range forecasts, $\operatorname{COV}\left(\hat{H}_{t+h}-H_{t+h}, \hat{L}_{t+h}-L_{t+h}\right)$ is positive. That is, the forecast errors of highs and lows tend to move in the same direction - an over-prediction (underprediction) of the high is likely to be accompanied by an over-prediction (under-prediction) of the low, and vice versa. The comovement of high and low forecast errors helps bring the variance of range forecast errors down to a level lower than those of $\hat{H}_{t+h}-H_{t+h}$ and $\hat{L}_{t+h}-L_{t+h}$. The comovement of $\hat{H}_{t+h}-H_{t+h}$ and $\hat{L}_{t+h}-L_{t+h}$ from the VECM, which explicitly links the high and the low together, is in general stronger than that from estimating the high and the low separately. It is only in the cases of the British and French indexes that the $\operatorname{COV}\left(\hat{H}_{t+h}-H_{t+h}\right.$, $\left.\hat{L}_{t+h}-L_{t+h}\right)$ associated with $\hat{R}_{t+h, A 1}$ is slightly less than those associated with the other two range forecasts. Further, the comovement of $\hat{H}_{t+h}-H_{t+h}$ and $\hat{L}_{t+h}-L_{t+h}$ that derived from $\hat{R}_{t+h, R V}$ is, on average, stronger than that from $\hat{R}_{t+h, S V}$.

The decomposition results corroborate the notion that, comparing with $\hat{R}_{t+h, A 1}$, the joint estimation of the high and the low offers incremental information for range forecasting. The information gain ameliorates range forecasts by reducing the variability of errors in forecasting highs and lows and increasing the comovement of these two forecast errors. The improvement in forecasting highs and lows is relevant for exercises that require information on extreme values of the underlying financial price - for example, for pricing of knock-out options and implementing trading rules such as the Channel rule, the resistant and support levels, and the Candlestick chart.

\section{An Illustration}

As mentioned in the introduction, range is an efficient estimator of volatility. In this section, we assess the ability of range forecasts examined in the previous section to predict volatility. Volatility forecasting is an active research area and has significant implications for financial market practitioners. Andersen et al. (2005) and Poon and Granger (2003) are two recent extensive surveys on the subject. ${ }^{12}$ Strictly speaking, the volatility of a stock index is an unobservable parameter that determines the index's observed variations. In this exercise, we consider implied volatility, which is commonly regarded as a market expectation of the unobservable volatility as the forecast object.

12 Poon and Granger (2005) review some practical issues in forecasting volatilities. 
For a given options contract, implied volatility is a volatility estimate recovered from an options pricing equation with information on the premium and other pricing variables including the strike, price of the underlying asset, interest rate, and time to maturity. The reported implied volatility value is typically compiled from the average of a few nearest-the-money calls and nearest-the-money puts, which are used as a proxy for at-the-money contracts. ${ }^{13}$ It is a common denominator of option prices that practitioners use to compare options of different types.

The implied volatilities under consideration are those of the European FTSE and DJI options contracts. The one-month and three-months calls and puts are included. The FTSE contract is traded on the Euronext.liffe London exchange and the DJI one is on the Chicago Board Options Exchange. Contract specifications are available on the exchanges' official websites. The implied volatility data were downloaded from the database Datastream. ${ }^{14}$ The forecasting period is from January 16, 2003 to June 1, 2004 - the same as the one examined in Section 4 . The volatility forecast derived from the range forecast is given by

$$
\left[\hat{R}_{t+h, j}^{2} /(4 \ln 2)\right]^{1 / 2},
$$

where $j=A 1, A 2, S V$, and $R V$. Since the implied volatility is annualized, we scale (7) accordingly and consider the scaled forecast ${ }^{15}$

$$
\hat{V}_{t+h, j}=\left[365 \hat{R}_{t+h, j}^{2} /(4 \ln 2)\right]^{1 / 2} .
$$

The comparison of the performance of the scaled forecasts based on the mean-squared forecast error criterion is presented in Table 11. The modified Diebold-Mariano statistic clearly indicates that, among the four scaled forecasts, $\hat{V}_{t+h, A 1}$ is the worst predictor of implied volatility. For the two puts and two calls of the FTSE and DJI options, the mean-squared forecast errors of $\hat{V}_{t+h, A 1}$ are significantly larger than those of the other three scaled forecasts. The results reiterate those reported in the previous section - the forecast $\hat{V}_{t+h, A 1}$ that ignores the interaction between

13 The number of individual nearest-the-money calls and nearest-the-money puts used in the industry to construct implied volatility varies from two to four. The use of at-the-money contracts is to alleviate issues related to volatility smile - which refers to the observation that at-the-money options have implied volatilities lower than other (out-of-money and in-the-money) options.

14 We were informed that DataStream uses a variant of the Black and Scholes model to construct implied volatility.

15 Usually, a $\sqrt{\mathrm{n}}$ factor is used to get an n-days ahead forecast from an implied volatility estimate. According to the specification of implied volatility, the day-adjustment factor to obtain the annualized volatility is 365 , which is different from the 250 or 252 factor used in, say, historical volatility calculation. We also conducted the forecast exercise using the factors 250 and 360 . The relative performance of these forecasts is qualitatively similar to those reported in the text and is available upon request. 
Table 11. Predicting Implied Volatility: Mean-Squared Forecast Errors

\begin{tabular}{|c|c|c|c|c|c|c|}
\hline & $\hat{V}_{t+h, A 1} / \hat{V}_{t+h, A 2}$ & $\hat{V}_{t+h, A 1} / \hat{V}_{t+h, S V}$ & $\hat{V}_{t+h, A 1} / \hat{V}_{t+h, R V}$ & $\hat{V}_{t+h, A 2} / \hat{V}_{t+h, S V}$ & $\hat{V}_{t+h, A 2} / \hat{V}_{t+h, R V}$ & $\hat{V}_{t+h, S V} / \hat{V}_{t+h, R V}$ \\
\hline \multicolumn{7}{|l|}{ FTSEP3: } \\
\hline $\mathrm{h}=1$ & $4.8186^{* *}$ & $4.7184 * *$ & $4.7273 * *$ & 0.5523 & 0.4195 & -1.4077 \\
\hline $\mathrm{h}=2$ & $4.2703 * *$ & $4.0965^{* *}$ & $4.0992 * *$ & 0.0190 & -0.0084 & -0.2737 \\
\hline $\mathrm{h}=4$ & $2.9861 * *$ & $2.8921 * *$ & $2.8869 * *$ & -0.4286 & -0.2224 & 1.3858 \\
\hline \multicolumn{7}{|l|}{ FTSEP6: } \\
\hline $\mathrm{h}=1$ & $4.7154 * *$ & $4.6019^{* *}$ & $4.6138^{* *}$ & 0.4926 & 0.3741 & -1.1501 \\
\hline $\mathrm{h}=2$ & $4.2386^{* *}$ & $4.0619^{* *}$ & $4.0660 * *$ & 0.1311 & 0.1056 & -0.1788 \\
\hline $\mathrm{h}=4$ & $2.9083^{* *}$ & $2.8172 * *$ & $2.8126^{* *}$ & -0.3390 & -0.1265 & 1.3518 \\
\hline \multicolumn{7}{|l|}{ FTSEC3: } \\
\hline $\mathrm{h}=1$ & $4.3422 * *$ & $4.2324 * *$ & $4.2595^{* *}$ & 1.1484 & 1.1318 & -0.3968 \\
\hline $\mathrm{h}=2$ & $4.0608^{* *}$ & $3.8179 * *$ & $3.8316^{* *}$ & 0.3700 & 0.4047 & 0.4258 \\
\hline $\mathrm{h}=4$ & $2.5977 * *$ & $2.4800 * *$ & $2.4762 * *$ & -0.1410 & 0.0646 & 1.5065 \\
\hline \multicolumn{7}{|l|}{ FTSEC6: } \\
\hline $\mathrm{h}=1$ & $4.1818^{* *}$ & $4.0552 * *$ & $4.0866^{* *}$ & 0.9430 & 0.9376 & -0.2651 \\
\hline $\mathrm{h}=2$ & $3.9579 * *$ & $3.6551^{* *}$ & $3.6724 * *$ & 0.2177 & 0.2649 & 0.4316 \\
\hline $\mathrm{h}=4$ & $2.5282 * *$ & $2.4091 * *$ & $2.4053 * *$ & 0.0063 & 0.2110 & 1.4574 \\
\hline \multicolumn{7}{|l|}{ DJIP3: } \\
\hline $\mathrm{h}=1$ & $8.2075^{* *}$ & $7.9874 * *$ & $8.0209 * *$ & -1.1143 & -0.9547 & $3.9752 * *$ \\
\hline $\mathrm{h}=2$ & $7.8096^{* *}$ & $8.1987 * *$ & $8.2150 * *$ & -0.6593 & -0.5309 & $3.2355^{* *}$ \\
\hline $\mathrm{h}=4$ & $6.9058^{* *}$ & $7.3453^{* *}$ & $7.3443^{* *}$ & 0.0086 & 0.0643 & 1.2953 \\
\hline \multicolumn{7}{|l|}{ DJIP6: } \\
\hline $\mathrm{h}=1$ & $8.3260 * *$ & $7.9700 * *$ & $8.0071 * *$ & $-1.7472 *$ & -1.5646 & $4.2421 * *$ \\
\hline $\mathrm{h}=2$ & $8.1255^{* *}$ & $8.4366^{* *}$ & $8.4571 * *$ & -0.9293 & -0.7980 & $3.2367 * *$ \\
\hline $\mathrm{h}=4$ & $7.0019 * *$ & $7.3448^{* *}$ & $7.3444^{* *}$ & 0.1651 & 0.1997 & 0.7237 \\
\hline \multicolumn{7}{|l|}{ DJIC3: } \\
\hline $\mathrm{h}=1$ & $8.8118^{* *}$ & $8.5227^{* *}$ & $8.5643 * *$ & -1.4942 & -1.2862 & $5.2420 * *$ \\
\hline $\mathrm{h}=2$ & $7.9323 * *$ & $8.2438^{* *}$ & $8.2643^{* *}$ & -0.7965 & -0.6479 & $4.0445^{* *}$ \\
\hline $\mathrm{h}=4$ & $6.7896^{* *}$ & $6.9931 * *$ & $6.9905^{* *}$ & -0.1955 & -0.1535 & 0.9790 \\
\hline \multicolumn{7}{|l|}{ DJIC6: } \\
\hline $\mathrm{h}=1$ & $8.4690 * *$ & $8.0698^{* *}$ & $8.1122 * *$ & $-1.8464 *$ & -1.6153 & $5.1834 * *$ \\
\hline $\mathrm{h}=2$ & $7.7821 * *$ & $7.9092 * *$ & $7.9345^{* *}$ & -1.0226 & -0.8728 & $3.8064 * *$ \\
\hline $\mathrm{h}=4$ & $6.7773^{* *}$ & $6.9368 * *$ & $6.9348 * *$ & 0.0293 & 0.0602 & 0.6002 \\
\hline
\end{tabular}

Note: The results of using range forecasts to predict implied volatility are reported. P3, P6, C3, and C6 give after the index labels FTSE and DJI denote puts and calls with maturities of 3 and 6 months. The modified Diebold Mariano statistics that compare the performance of two forecasts based on the mean-squared forecast error criterion are presented. A positive test statistic indicates that the first on of the forecast pair has a mean-squared forecast error larger than the second one. "**" and "*" indicate significance at the 5\% and $10 \%$ level respectively. 
highs and lows do not perform well in the forecast competition.

Compared with the VECM-based scaled forecasts, the scaled forecast $\hat{V}_{t+h, A 2}$ based on the ARMA structure of range performs slightly worse for the FTSE contracts but slightly better for the DJI ones. With the exception of two cases (DJIP6 and DJIC6 at $\mathrm{h}=1$ ), the differences between $\hat{V}_{t+h, A 2}$ and two VECM-based forecasts are not statistically significant. Again, the results are suggestive of the VECM short-run dynamics may not be stable over time and the forecast $\hat{V}_{t+h, A 2}$ which incorporates only the empirical long-run relationship between highs and lows is not totally dominated by the VECM-based $\hat{V}_{t+h, R V}$ and $\hat{V}_{t+h, S V}$. Nonetheless, the relative performance of $\hat{V}_{t+h, A 2}$ is not as good as the relative performance of $\hat{R}_{t+h, A 2}$ reported in Table 5. There are differences in forecasting ranges and forecasting implied volatilities such that these forecasts perform differently in these two cases.

Between the two VECM-based forecasts, the recursive $\hat{V}_{t+h, R V}$ forecast dominates the simple $\hat{V}_{t+h, S V}$ one for the DJI options and has a significantly smaller mean-squared forecast error for both one-period and two-period ahead forecasts. However, the abilities of these two VECMbased predictors are quite similar and their mean-squared forecast errors are not significantly different from each other for the FTSE options.

The ability of the scaled forecasts to predict the change in the direction of implied volatility is reported in Table 12. The statistics show that, in general, the four scaled forecasts can predict the change in the direction of implied volatility. The proportion of cases in which the forecasts can make a correct directional prediction with more than a $50 \%$ chance is between two thirds $\left(\hat{V}_{t+h, A 1}\right)$ and five sixths $\left(\hat{V}_{t+h, S V}\right)$. Comparing the results in Table $6, \hat{V}_{t+h, A 1}$ gives a higher percentage of correct directional forecasts than $\hat{R}_{t+h, A 1}$. Indeed, $\hat{V}_{t+h, A 1}$ is significantly better than the $50 \%$ mark in two thirds of the cases and $\hat{R}_{t+h, A 1}$ is worse than the $50 \%$ mark in more than two thirds of the cases. On the other hand, the correct directional forecast percentages of $\hat{V}_{t+h, A 2}$, $\hat{V}_{t+h, S V}$, and $\hat{V}_{t+h, R V}$ are much lower than those of $\hat{R}_{t+h, A 2}, \hat{R}_{t+h, S V}$ and $\hat{R}_{t+h, R V}$. The percentages of these scaled forecasts to predict changes in the direction of implied volatility are no higher than $60 \%$ while those of the corresponding range forecasts are usually no lower than $70 \%$. Thus, the 
range forecast performance cannot be directly used to infer the performance of forecasting implied volatility.

Table 12. Predicting Implied Volatility: Direction of Change Statistics

\begin{tabular}{|c|c|c|c|c|c|c|c|c|}
\hline & $\hat{V}_{t+h, A 1}$ & $\begin{array}{c}\text { (Correct } \\
\%)\end{array}$ & $\hat{V}_{t+h, A 2}$ & $\begin{array}{c}\text { Correct } \\
\%)\end{array}$ & $\hat{V}_{t+h, S V}$ & $\begin{array}{c}\text { (Correct } \\
\%)\end{array}$ & $\hat{V}_{t+h, R V}$ & $\begin{array}{c}\text { (Correct } \\
\%)\end{array}$ \\
\hline \multicolumn{9}{|l|}{ FTSEP3: } \\
\hline $\mathrm{h}=1$ & 1.1793 & $53.16 \%$ & $2.3586^{* *}$ & $56.32 \%$ & $3.0019 * *$ & $58.05 \%$ & $2.3586^{* *}$ & $56.32 \%$ \\
\hline $\mathrm{h}=2$ & $2.6305 * *$ & $57.06 \%$ & $2.2010 * *$ & $55.91 \%$ & $3.1673 * *$ & $58.50 \%$ & $2.9526 * *$ & $57.93 \%$ \\
\hline $\mathrm{h}=4$ & 1.1306 & $53.04 \%$ & $2.5304 * *$ & $56.81 \%$ & $3.1765^{* *}$ & $58.55 \%$ & $2.7457 * *$ & $57.39 \%$ \\
\hline \multicolumn{9}{|l|}{ FTSEP6: } \\
\hline $\mathrm{h}=1$ & $2.3586^{* *}$ & $56.32 \%$ & $2.1442 * *$ & $55.75 \%$ & $3.2163^{* *}$ & $58.62 \%$ & $2.7875^{* *}$ & $57.47 \%$ \\
\hline $\mathrm{h}=2$ & $1.6642 * *$ & $54.47 \%$ & $1.7715 * *$ & $54.76 \%$ & $2.2010^{* *}$ & $55.91 \%$ & $1.7715 * *$ & $54.76 \%$ \\
\hline $\mathrm{h}=4$ & 1.0229 & $52.75 \%$ & $1.9920 * *$ & $55.36 \%$ & $2.7457 * *$ & $57.39 \%$ & $2.5304 * *$ & $56.81 \%$ \\
\hline \multicolumn{9}{|l|}{ FTSEC3: } \\
\hline $\mathrm{h}=1$ & $1.7154^{* *}$ & $54.60 \%$ & $1.8226^{* *}$ & $54.89 \%$ & $3.0019^{* *}$ & $58.05 \%$ & $2.0370 * *$ & $55.46 \%$ \\
\hline $\mathrm{h}=2$ & $2.5231 * *$ & $56.77 \%$ & $2.8452 * *$ & $57.64 \%$ & $3.5967^{* *}$ & $59.65 \%$ & $3.3820 * *$ & $59.08 \%$ \\
\hline $\mathrm{h}=4$ & $1.5613 *$ & $54.20 \%$ & $2.9611 * *$ & $57.97 \%$ & $3.1765^{* *}$ & $58.55 \%$ & $3.2841 * *$ & $58.84 \%$ \\
\hline \multicolumn{9}{|l|}{ FTSEC6: } \\
\hline $\mathrm{h}=1$ & $1.5010^{*}$ & $54.02 \%$ & $1.8226 * *$ & $54.89 \%$ & $2.8947 * *$ & $57.76 \%$ & $2.4659 * *$ & $56.61 \%$ \\
\hline $\mathrm{h}=2$ & $1.9863^{* *}$ & $55.33 \%$ & $1.9863^{* *}$ & $55.33 \%$ & $2.5231^{* *}$ & $56.77 \%$ & $2.4157 * *$ & $56.48 \%$ \\
\hline $\mathrm{h}=4$ & 0.4845 & $51.30 \%$ & $2.3150 * *$ & $56.23 \%$ & $2.9611 * *$ & $57.97 \%$ & $2.7457 * *$ & $57.39 \%$ \\
\hline \multicolumn{9}{|l|}{ DJIP3: } \\
\hline $\mathrm{h}=1$ & 1.0752 & $52.89 \%$ & -0.4301 & $48.84 \%$ & 0.2150 & $50.58 \%$ & -0.3226 & $49.13 \%$ \\
\hline $\mathrm{h}=2$ & $2.4227^{* *}$ & $56.52 \%$ & $1.5613^{*}$ & $54.20 \%$ & $1.8843^{* *}$ & $55.07 \%$ & $1.6690 * *$ & $54.49 \%$ \\
\hline $\mathrm{h}=4$ & $1.8898 * *$ & $55.10 \%$ & $2.6458 * *$ & $57.14 \%$ & $2.7537 * *$ & $57.43 \%$ & $2.7537 * *$ & $57.43 \%$ \\
\hline \multicolumn{9}{|l|}{ DJIP6: } \\
\hline $\mathrm{h}=1$ & $1.3978^{*}$ & $53.76 \%$ & 0.4301 & $51.16 \%$ & 0.7526 & $52.02 \%$ & 0.2150 & $50.58 \%$ \\
\hline $\mathrm{h}=2$ & $2.5304^{* *}$ & $56.81 \%$ & $1.5613^{*}$ & $54.20 \%$ & $1.7767 * *$ & $54.78 \%$ & $1.6690 * *$ & $54.49 \%$ \\
\hline $\mathrm{h}=4$ & $1.4579 *$ & $53.94 \%$ & $2.3218^{* *}$ & $56.27 \%$ & $2.9697 * *$ & $58.02 \%$ & $2.8617^{* *}$ & $57.73 \%$ \\
\hline \multicolumn{9}{|l|}{ DJIC3: } \\
\hline $\mathrm{h}=1$ & 0.2150 & $50.58 \%$ & 0.6451 & $51.73 \%$ & 0.8602 & $52.31 \%$ & 0.6451 & $51.73 \%$ \\
\hline $\mathrm{h}=2$ & $3.0688 * *$ & $58.26 \%$ & $2.4227^{* *}$ & $56.52 \%$ & $2.6381^{* *}$ & $57.10 \%$ & $2.6381 * *$ & $57.10 \%$ \\
\hline $\mathrm{h}=4$ & $1.9978^{* *}$ & $55.39 \%$ & $2.4298 * *$ & $56.56 \%$ & $2.5378^{* *}$ & $56.85 \%$ & $2.5378 * *$ & $56.85 \%$ \\
\hline \multicolumn{9}{|l|}{ DJIC6: } \\
\hline $\mathrm{h}=1$ & -0.1075 & $49.71 \%$ & -0.2150 & $49.42 \%$ & $1.2902 *$ & $53.47 \%$ & 0.7526 & $52.02 \%$ \\
\hline $\mathrm{h}=2$ & $2.3150 * *$ & $56.23 \%$ & 0.8076 & $52.17 \%$ & 1.2383 & $53.33 \%$ & 1.1306 & $53.04 \%$ \\
\hline $\mathrm{h}=4$ & 0.8099 & $52.19 \%$ & $1.4579^{*}$ & $53.94 \%$ & $2.2138^{* *}$ & $55.98 \%$ & $1.8898 * *$ & $55.10 \%$ \\
\hline
\end{tabular}

Note: The direction of change statistics for testing the hypothesis of the proportion of forecasts that correctly predict the implied volatility directional change is $50 \%$ are reported. P3, P6, C3, and C6 give after the index labels FTSE and DJI denote puts and calls with maturities of 3 and 6 months. "**" and "*" indicate significance at the $5 \%$ and $10 \%$ level respectively. The observed proportions of correct directional forecasts are presented in columns labeled (correct \%). 
A statistical comparison of the scaled forecasts' abilities to predict the change in the direction of implied volatility is presented in Table 13. In this case, the performance of $\hat{R}_{t+h, A 1}$ is not substantially worse than that of other scaled forecasts. The result is in contrast to its relative performance reported in the cases considered so far. Only in a few instances - two cases against $\hat{V}_{t+h, A 2}$, five against $\hat{V}_{t+h, S V}$, and two against $\hat{V}_{t+h, R V}$, that the implied volatility forecast derived from individual high and low forecasts has a significant deterioration in the chance to make a correct directional prediction. In this round of comparison, $\hat{V}_{t+h, S V}$ fares the best. It performs

Table 13. Predicting Implied Volatility: Comparing Direction of Change Statistics

\begin{tabular}{rcccccc}
\hline & $\hat{V}_{t+h, A 1} / \hat{V}_{t+h, A 2}$ & $\hat{V}_{t+h, A 1} / \hat{V}_{t+h, S V}$ & $\hat{V}_{t+h, A 1} / \hat{V}_{t+h, R V}$ & $\hat{V}_{t+h, A 2} / \hat{V}_{t+h, S V}$ & $\hat{V}_{t+h, A 2} / \hat{V}_{t+h, R V}$ & $\hat{V}_{t+h, S V} / \hat{V}_{t+h, R V}$ \\
\hline FTSEP3: & & & & & & \\
$\mathrm{h}=1$ & 1.2385 & $1.8287^{*}$ & 1.2385 & 1.2256 & 0.0000 & $-2.1321^{* *}$ \\
$\mathrm{~h}=2$ & -0.4514 & 0.5681 & 0.3498 & $2.3698^{* *}$ & $1.7119^{*}$ & -1.0000 \\
$\mathrm{~h}=4$ & 1.4249 & $1.8298^{*}$ & 1.4817 & 1.0622 & 0.3619 & $-2.0657^{* *}$ \\
FTSEP6: & & & & & \\
$\mathrm{h}=1$ & -0.2459 & 0.9298 & 0.4845 & $2.2491^{* *}$ & 1.5027 & -1.6369 \\
$\mathrm{~h}=2$ & 0.1216 & 0.6185 & 0.1296 & 0.9424 & 0.0000 & -1.4205 \\
$\mathrm{~h}=4$ & 1.1020 & $1.7201^{*}$ & 1.5493 & $1.7322^{*}$ & 1.5281 & -1.4293 \\
FTSEC3: & & & & & & \\
$\mathrm{h}=1$ & 0.1169 & 1.3432 & 0.3507 & $2.6917^{* *}$ & 0.6319 & $-3.0352^{* *}$ \\
$\mathrm{~h}=2$ & 0.3451 & 1.1805 & 0.9558 & $2.3800^{* *}$ & $1.6798^{*}$ & -1.0000 \\
$\mathrm{~h}=4$ & 1.4804 & 1.5791 & $1.7407^{*}$ & 0.5734 & 1.0001 & 1.0001 \\
FTSEC6: & & & & & \\
$\mathrm{h}=1$ & 0.3661 & 1.5683 & 1.1167 & $2.6966^{* *}$ & $1.9045^{*}$ & $-2.0087^{* *}$ \\
$\mathrm{~h}=2$ & 0.0000 & 0.6493 & 0.5236 & 1.2152 & 0.9424 & -0.5757 \\
$\mathrm{~h}=4$ & $2.183 * *$ & $2.5743^{* *}$ & $2.3535^{* *}$ & $2.2033^{* *}$ & $1.6622^{*}$ & -1.4293 \\
DJIP3: & & & & & \\
$\mathrm{h}=1$ & -1.5887 & -0.9056 & -1.5038 & 1.5027 & 0.3011 & $-2.2491^{* *}$ \\
$\mathrm{~h}=2$ & -0.8717 & -0.5608 & -0.8069 & 0.9038 & 0.3320 & -1.0000 \\
$\mathrm{~h}=4$ & 0.7076 & 0.7819 & 0.7819 & 0.5734 & 0.5734 &. \\
DJIP6: & & & & & & \\
$\mathrm{h}=1$ & -1.0837 & -0.6877 & -1.3068 & 0.7271 & -0.5768 & $-2.2491^{* *}$ \\
$\mathrm{~h}=2$ & -1.1006 & -0.8673 & -1.0162 & 0.5329 & 0.3003 & -1.0000 \\
$\mathrm{~h}=4$ & 0.9034 & 1.4923 & 1.3895 & $2.5890^{* *}$ & $2.3363^{* *}$ & -1.0001 \\
DJIC3: & & & & & & -0.8161 \\
$\mathrm{~h}=1$ & 0.4583 & 0.6541 & 0.4467 & 0.3775 & 0.0000 & - \\
$\mathrm{h}=2$ & -0.6776 & -0.4697 & -0.4633 & 0.5757 & 0.5757 & 0.0000 \\
$\mathrm{~h}=4$ & 0.4383 & 0.5324 & 0.5324 & 0.3747 & 0.3747 & -1.0000 \\
DJIC6: & & & & & & \\
$\mathrm{h}=1$ & -0.1153 & 1.4291 & 0.9056 & $2.7720^{* *}$ & $1.9721^{* *}$ & $-2.2491^{* *}$ \\
$\mathrm{~h}=2$ & -1.5753 & -1.1975 & -1.3287 & 0.8937 & 0.6867 & -1.0000 \\
$\mathrm{~h}=4$ & 0.6220 & 1.4449 & 1.1371 & 1.6333 & 1.0708 & $-1.7697^{*}$ \\
\hline & & & & & &
\end{tabular}


Note: The modified Diebold Mariano statistics that compare the directional forecast performance of two scaled forecasts of implied volatility are presented. A positive test statistic indicates that the second one of the forecast pair has a proportion of correct directional predictions larger than the first one. "**" and "**" indicate significance at the $5 \%$ and $10 \%$ level respectively.

better than $\hat{V}_{t+h, A 2}$ and $\hat{V}_{t+h, R V}$ in a good numbers of cases. The other VECM-based forecast $\hat{V}_{t+h, R V}$ also delivers a stronger performance than $\hat{V}_{t+h, A 2}$. In contract to the mean-squared forecast error results, the VECM-based forecasts of implied volatility are better than $\hat{V}_{t+h, A 2}$, which does not incorporate short-run high and low dynamics. Thus, in predicting the change in the direction of implied volatility, it pays to consider the short-run dynamics in VECM, though recursively updating the dynamics does not improve the forecast performance.

\section{Concluding Remarks}

In this exercise we observe that daily highs and lows of stock prices do not diverge over time and, hence, adopt the cointegration framework to model the daily high, the daily low, and the associated daily range data. Most of the existing studies focus on the price range variable itself and its capacity to extract the unobservable return volatility. By examining the variables simultaneously, the current study yields information on not just the range itself but also information about its components - the daily high and the daily low. Thus, our results are relevant to a wide class of applications that require information beyond the range variable.

Our empirical results attest to the importance of incorporating high-low interactions in modeling the range variable. The in-sample performance of the high-low VECM is quite good. The out-of-sample forecast performance, however, deserves some discussion. The decomposition exercise indicates that the joint estimation improves the performance of the high and low forecasts. Thus, the VECM is a good candidate to consider if the application requires information on highs and lows.

However, the VECM-based range forecast does not always dominate other alternative forecasts. Indeed, there are instances in which forecasts from simple ARMA range models perform better. One observation is that forecast rankings depend on evaluation criteria and the variables being forecasted. For instance, even if a forecast is a good predictor of range, it may 
not be automatically a good predictor of implied volatility. Putting all these together, the insample results are more supportive of the VECM specification than the out-of-sample results.

How should we interpret the disparate in-sample and out-of-sample performance? One possibility is that the high-low model is not stable over time and the instability makes it difficult to translate good in-sample performance to good out-of-sample results. A more relevant question is how much weight one has to put on out-of-sample evidence. Recently, Inoue and Kilian (2004) assess the relative usefulness of out-of-sample versus in-sample tests. These authors observe a widely known result that significant in-sample evidence does not guarantee significant out-of-sample predictability. They argue that in-sample tests have higher power and show that in-sample results are typically more credible than out-of-sample results. Another difficulty in interpreting forecast performance is pointed out by Clements and Hendry (2001) - they show that an incorrect but simple model may outperform a correct model in forecasting.

We do not mean to overplay the relevance of the high-low VECM and, hence, downplay the out-of-sample results. Indeed, the VECM delivers reasonable out-of-sample range forecasts and it offers even better high and low forecasts. In this respect, further work on interactions between highs, lows, and ranges is warranted. Further, we consider neither structural models nor nonlinear specifications. These alternative modeling strategies may offer additional information on the dynamics of highs, lows, and ranges.

While we used range forecasts to predict implied volatility, we neither examine the link between range and return volatility in detail nor the practical relevancy of using high and low forecasts in the context of, say, exotic options pricing and technical trading. Conceivably, additional insights can be gained from extending the current exercise to analyze return volatility, options pricing, and technical trading. 


\section{Appendix: Evaluating Forecast Accuracy}

The original Diebold-Mariano statistic (Diebold and Mariano, 1995) is constructed as follows. Let $e_{i t}$ and $e_{j t}$ be the forecast errors of the forecasts generated from models $i$ and $j$, respectively. The squared forecast error is defined as

$$
L\left(e_{i t}\right)=e_{i t}^{2} \text {, and } L\left(e_{j t}\right)=e_{j t}^{2}
$$

Let

$$
d_{t}=L\left(y_{t}\right)-L\left(z_{t}\right)
$$

be the loss differential series. Testing whether the performance of the forecast series from model $i$ is different from that of model $j$, it is equivalent to testing whether the population mean of the loss differential series $d_{t}$ is zero; that is $E d_{t}=0$.

Under the assumptions of covariance stationarity and short-memory for $d_{t}$, the null hypothesis of equal forecast performance can be evaluated using the statistic

$$
\bar{d} / V(\hat{\bar{d}})^{1 / 2},
$$

where $V(\hat{\bar{d}})=2 \pi \sum_{\tau=-(T-1)}^{(T-1)} l(\tau / S(T)) \sum_{t=|\tau|+1}^{T}\left(d_{t}-\bar{d}\right)\left(d_{t-|\tau|}-\bar{d}\right), l(\tau / S(T))$ is the lag window, $S(T)$ is the truncation lag, and $T$ is the number of observations. Different lag-window specifications can be applied, such as the Barlett or the quadratic spectral kernels, in combination with a datadependent lag-selection procedure (Andrews, 1991). It can be shown that the statistic has an asymptotic standard normal distribution.

For comparing multiple-step ahead forecasts, Harvey et. al. (1997) propose a modified Dieold-Mariano statistic

$$
\left[\frac{T+1-2 h+T^{-1} h(h-1)}{T}\right]^{1 / 2} \bar{d} / V_{h}(\hat{\bar{d}})^{1 / 2},
$$

where $V_{h}(\hat{\bar{d}})=T^{-1}\left[\gamma_{o}+2 \sum_{k=1}^{h-1} \gamma_{k}\right], \gamma_{k}$ is the $k$ th autocovariance of $d_{t}$, and $h$ is the forecast horizon. The modified statistic has an asymptotic $t_{T-1}$ distribution.

For the direction of change statistic, the loss differential series is defined as follows: $d_{t}$ takes a value of one if the forecast series correctly predicts the direction of change, otherwise it will take a value of zero. Hence, a value of $\bar{d}$ significantly larger than 0.5 indicates that the 
forecast has the ability to predict the direction of change; on the other hand, if the statistic is significantly less than 0.5 , the forecast tends to give the wrong direction of change. In large samples, the studentized version of the test statistic,

$$
(\bar{d}-0.5) / \sqrt{0.25 / T},
$$

is distributed as a standard normal. Further, the statistics (A3) and (A4) can be modified to compare the abilities of different procedures to predict the direction of change. 


\section{References}

Abhyankar, A., Sarno, L. and Valente, G., 2005. Exchange rates and fundamentals: evidence on the economic value of predictability. Journal of International Economics 66, pp. 325348.

Alizadeh, S., Brandt, M.W. and Diebold, F.X., 2002. Range-based estimation of stochastic volatility models. Journal of Finance 57, pp. 1047-1091.

Andersen, T.G., Bollerslev, T., Christoffersen, P.F. and Diebold, F.X., 2005. Volatility forecasting. NBER Working Paper 11188.

Beckers, S., 1983. Variances of security price returns based on high, low, and closing prices. The Journal of Business 56, pp. 97-112.

Brandt, M.W. and Diebold, F.X., 2003. A no-arbitrage approach to range-based estimation of return covariances and correlations. PIER Working Paper 03-013.

Brunetti, C. and Lildholdt, P.M., 2005. Relative efficiency of return- and range-based volatility estimators, manuscript, Johns Hopkins University.

Cheung, Y.-W., 2007. An Empirical Model of Daily Highs and Lows. International Journal of Finance and Economics 12, pp. 1-20.

Cheung, Y.-W. and Lai, K.S., 1995. Lag order and critical values of the Augmented DickeyFuller test. Journal of Business \& Economic Statistics 13, pp. 277-280.

Cheung, Y.-W. and Wong, C.Y.P., 2000. A survey of market practitioners' views on exchange rate dynamics. Journal of International Economics 51, pp. 401-419.

Cheung, Y.-W. and Chinn, M.D., 2001. Currency traders and exchange rate dynamics: A survey of the US market. Journal of International Money and Finance 20, pp. 439-471.

Chinn, M.D. and Meese, R.A., 1995. Banking on currency forecasts: How predictable is change in money? Journal of International Economics 38, pp. 161-178.

Christoffersen, P.F. and Diebold, F.X., 1998. Cointegration and long-horizon forecasting. Journal of Business and Economic Statistics 16, pp. 450-58.

Chou, R.Y., 2005. Forecasting financial volatilities with extreme values: the conditional autoregressive range (CARR) model. Journal of Money, Credit \& Banking 37, pp. 561 582.

Clements, M.P., Hendry, D.F., 2001. Forecasting with Difference and Trend Stationary Models. The Econometric Journal 4, pp. S1-S19. 
Diebold, F.X. and Mariano, R.S., 1995. Comparing predictive accuracy. Journal of Business \& Economic Statistics 13, pp. 253-263.

Edwards, R.D. and Magee, J., 1997. Technical analysis of stock trends, $7^{\text {th }}$ ed. New York : Amacom.

Engle, R.F. and Gallo, G.M., 2003. A multiple indicators model for volatility using intra-daily data. NBER Working Paper 10117.

Fernandes, M., de Sá Mota, B. and Rocha, G., 2005. A multivariate conditional autoregressive range model. Economics Letters 86, pp. 435-440.

Gallant, A.R., Hsu, C.T. and Tauchen, G., 1999. Using daily range data to calibrate volatility diffusions and extract the forward integrated variance. Review of Economics \& Statistics 81, pp. 617-631.

Garman, M.B. and Klass, M.J., 1980. On the estimation of security price volatilities from historical data. The Journal of Business 53, pp.67-78.

Harvey, D., Leybourne, S. and Newbold, P., 1997. Testing the equality of prediction mean squared errors. International Journal of Forecasting 13, pp.281-291.

Inoue, A. and Kilian, L., 2004. In-sample or out-of-sample tests of predictability: which one should we use? Econometric Reviews 23, pp.371-402.

Johansen, S., 1991. Estimation and hypothesis testing of cointegration vectors in Gaussian vector autoregressive models. Econometrica 59, pp. 1551-1580.

Johansen, S. and Juselius, K., 1990. Maximum likelihood estimation and inference on cointegration - with applications to the demand for money. Oxford Bulletin of Economics \& Statistics 52, pp.169-210.

Kunitomo, N., 1992. Improving the Parkinson method of estimating security price volatilities. The Journal of Business 65, pp. 295-302.

Leitch, G. and Tanner, J.E., 1991. Economic forecast evaluation: profits versus the conventional error measures. The American Economic Review 81, pp.580-590.

Mark, N.C., 1995. Exchange rates and fundamentals: evidence on long-horizon predictability. American Economic Review 85, pp.201-218.

Murphy, J.J., 1986. Technical analysis of the futures markets: A comprehensive guide to trading methods and applications. New York : New York Institute of Finance.

Parkinson, M., 1980. The extreme value method for estimating the variance of the rate of return. The Journal of Business 53, pp.61-65. 
Parkinson, M., 1977. Option pricing: The American put. The Journal of Business 50, pp. 21-36.

Poon, S.H. and Granger, C.W.J., 2003. Forecasting volatility in financial markets: A review. Journal of Economic Literature 41, pp.478-539.

Poon, S.H. and Granger, C., 2005. Pratical issues in forecasting volatility. Financial Analysts Journal 61, pp. 45-56.

Pring, M.J., 2002. Technical analysis explained: The successful investor's guide to spotting investment trends and turning points, $4^{\text {th }}$ ed. New York: McGraw-Hill.

Rogers, L.C.G. and Satchell, S.E., 1991. Estimating variance from high, low and closing prices. The Annals of Applied Probability 1, pp. 504-512.

Taylor, M.P. and Allen, H., 1992. The use of technical analysis in the foreign exchange market. Journal of International Money and Finance 11, pp. 304-314.

Yang, D. and Zhang, Q., 2000. Drift-independent volatility estimation based on high, low, open, and close prices. The Journal of Business 73, pp. 477-491. 


\section{CESifo Working Paper Series}

for full list see www.cesifo-group.org/wp

(address: Poschingerstr. 5, 81679 Munich, Germany, office@cesifo.de)

2325 Helmuth Cremer, Philippe De Donder, Dario Maldonado and Pierre Pestieau, Forced Saving, Redistribution and Nonlinear Social Security Schemes, June 2008

2326 M. Hashem Pesaran and Paolo Zaffaroni, Optimal Asset Allocation with Factor Models for Large Portfolios, June 2008

2327 Harald Badinger and Peter Egger, Horizontal versus Vertical Interdependence in Multinational Activity, June 2008

2328 Jan K. Brueckner and Harris Selod, A Theory of Urban Squatting and Land-Tenure Formalization in Developing Countries, June 2008

2329 Paolo M. Panteghini, Corporate Debt, Hybrid Securities and the Effective Tax Rate, June 2008

2330 Guglielmo Maria Caporale, Juncal Cuñado and Luis A. Gil-Alana, Modelling Long-Run Trends and Cycles in Financial Time Series Data, June 2008

2331 Avi Ben-Bassat and Momi Dahan, Social Identity and Voter Turnout, June 2008

2332 Martin R. West and Ludger Wößmann, "Every Catholic Child in a Catholic School”: Historical Resistance to State Schooling, Contemporary Private Competition, and Student Achievement across Countries, June 2008

2333 Erkki Koskela and Panu Poutvaara, Outsourcing and Labor Taxation in Dual Labor Markets, June 2008

2334 Philippe Choné and Laurent Linnemer, Optimal Litigation Strategies with Signaling and Screening, June 2008

2335 Albert Solé-Ollé and Pilar Sorribas-Navarro, Does Partisan Alignment Affect the Electoral Reward of Intergovernmental Transfers?, June 2008

2336 Antonio Cabrales and Piero Gottardi, Markets for Information: Of Inefficient Firewalls and Efficient Monopolies, June 2008

2337 Sumon Majumdar and Sharun W. Mukand, The Leader as Catalyst - on Leadership and the Mechanics of Institutional Change, June 2008

2338 Ulrich Hange, Tax Competition, Elastic Labor Supply, and Growth, June 2008

2339 Guy Laroque and Bernard Salanié, Does Fertility Respond to Financial Incentives?, June 2008 
2340 Adriano Paggiaro, Enrico Rettore and Ugo Trivellato, The Effect of Extending the Duration of Eligibility in an Italian Labour Market Programme for Dismissed Workers, June 2008

2341 Helmut Seitz, Minimum Standards, Fixed Costs and Taxing Autonomy of Subnational Governments, June 2008

2342 Robert S. Chirinko, Leo de Haan and Elmer Sterken, Asset Price Shocks, Real Expenditures, and Financial Structure: A Multi-Country Analysis, July 2008

2343 Wolfgang Leininger, Evolutionarily Stable Preferences in Contests, July 2008

2344 Hartmut Egger and Udo Kreickemeier, Fairness, Trade, and Inequality, July 2008

2345 Ngo Van Long and Bodhisattva Sengupta, Yardstick Competition, Corruption, and Electoral Incentives, July 2008

2346 Florian Baumann, Employment Protection: The Case of Limited Enforceability, July 2008

2347 Alessandro Balestrino, Cinzia Ciardi and Claudio Mammini, On the Causes and Consequences of Divorce, July 2008

2348 Dirk Schindler and Benjamin Weigert, Insuring Educational Risk: Opportunities versus Income, July 2008

2349 Lammertjan Dam and Ben J. Heijdra, The Environmental and Macroeconomic Effects of Socially Responsible Investment, July 2008

2350 Avner Greif, Contract Enforcement and Institutions among the Maghribi Traders: Refuting Edwards and Ogilvie, July 2008

2351 Helmuth Cremer, Philippe De Donder, Dario Maldonado and Pierre Pestieau, Habit Formation and Labor Supply, July 2008

2352 Francesco Menoncin and Paolo M. Panteghini, The Johansson-Samuelson Theorem in General Equilibrium: A Rebuttal, July 2008

2353 Michael Kaganovich and Itzhak Zilcha, Alternative Social Security Systems and Growth, July 2008

2354 Keith Blackburn, Kyriakos C. Neanidis and M. Emranul Haque, Corruption, Seigniorage and Growth: Theory and Evidence, July 2008

2355 Edward Castronova, A Test of the Law of Demand in a Virtual World: Exploring the Petri Dish Approach to Social Science, July 2008

2356 Harald Badinger and Peter Egger, GM Estimation of Higher-Order Spatial Autoregressive Processes in Cross-Section Models with Heteroskedastic Disturbances, July 2008 
2357 Wolfgang Buchholz and Jan Schumacher, Discounting the Long-Distant Future: A Simple Explanation for the Weitzman-Gollier-Puzzle, July 2008

2358 Luca Anderlini, Leonardo Felli and Alessandro Riboni, Statute Law or Case Law?, July 2008

2359 Guglielmo Maria Caporale, Davide Ciferri and Alessandro Girardi, Are the Baltic Countries Ready to Adopt the Euro? A Generalised Purchasing Power Parity Approach, July 2008

2360 Erkki Koskela and Ronnie Schöb, Outsourcing of Unionized Firms and the Impacts of Labour Market Policy Reforms, July 2008

2361 Francisco Alvarez-Cuadrado and Ngo Van Long, A Permanent Income Version of the Relative Income Hypothesis, July 2008

2362 Gabrielle Demange, Robert Fenge and Silke Uebelmesser, Financing Higher Education and Labor Mobility, July 2008

2363 Alessandra Casarico and Alessandro Sommacal, Labor Income Taxation, Human Capital and Growth: The Role of Child Care, August 2008

2364 Antonis Adam, Manthos D. Delis and Pantelis Kammas, Fiscal Decentralization and Public Sector Efficiency: Evidence from OECD Countries, August 2008

2365 Stefan Voigt, The (Economic) Effects of Lay Participation in Courts - A Cross-Country Analysis, August 2008

2366 Tobias König and Andreas Wagener, (Post-)Materialist Attitudes and the Mix of Capital and Labour Taxation, August 2008

2367 Ximing Wu, Andreas Savvides and Thanasis Stengos, The Global Joint Distribution of Income and Health, August 2008

2368 Alejandro Donado and Klaus Wälde, Trade Unions Go Global!, August 2008

2369 Hans Gersbach and Hans Haller, Exit and Power in General Equilibrium, August 2008

2370 Jan P.A.M. Jacobs and Jan-Egbert Sturm, The Information Content of KOF Indicators on Swiss Current Account Data Revisions, August 2008

2371 Oliver Hülsewig, Johannes Mayr and Timo Wollmershäuser, Forecasting Euro Area Real GDP: Optimal Pooling of Information, August 2008

2372 Tigran Poghosyan and Jakob de Haan, Determinants of Cross-Border Bank Acquisitions in Transition Economies: A Latent Class Analysis, August 2008

2373 David Anthoff and Richard S.J. Tol, On International Equity Weights and National Decision Making on Climate Change, August 2008 
2374 Florian Englmaier and Arno Schmöller, Reserve Price Formation in Online Auctions, August 2008

2375 Karl Farmer, Birgit Friedl and Andreas Rainer, Effects of Unilateral Climate Policy on Terms of Trade, Capital Accumulation, and Welfare in a World Economy, August 2008

2376 Monika Bütler, Stefan Staubli and Maria Grazia Zito, The Role of the Annuity’s Value on the Decision (Not) to Annuitize: Evidence from a Large Policy Change, August 2008

2377 Inmaculada Martínez-Zarzoso, The Impact of Urbanization on $\mathrm{CO}_{2}$ Emissions: Evidence from Developing Countries, August 2008

2378 Brian Roberson and Dmitriy Kvasov, The Non-Constant-Sum Colonel Blotto Game, August 2008

2379 Ian Dew-Becker, How Much Sunlight Does it Take to Disinfect a Boardroom? A Short History of Executive Compensation Regulation, August 2008

2380 Cécile Aubert, Oliver Falck and Stephan Heblich, Subsidizing National Champions: An Evolutionary Perspective, August 2008

2381 Sebastian Buhai, Miguel Portela, Coen Teulings and Aico van Vuuren, Returns to Tenure or Seniority?, August 2008

2382 Erkki Koskela and Jan König, Flexible Outsourcing, Profit Sharing and Equilibrium Unemployment, August 2008

2383 Torberg Falch and Justina AV Fischer, Does a Generous Welfare State Crowd out Student Achievement? Panel Data Evidence from International Student Tests, September 2008

2384 Pedro Gomes and François Pouget, Corporate Tax Competition and the Decline of Public Investment, September 2008

2385 Marko Koethenbuerger, How Do Local Governments Decide on Public Policy in Fiscal Federalism? Tax vs. Expenditure Optimization, September 2008

2386 Ronald McKinnon and Gunther Schnabl, China’s Exchange Rate Impasse and the Weak U.S. Dollar, September 2008

2387 Yan-Leung Cheung, Yin-Wong Cheung and Alan T.K. Wan, A High-Low Model of Daily Stock Price Ranges, September 2008 